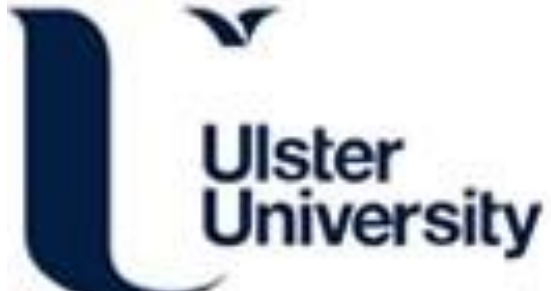

\section{Critical review of nutrition, blood pressure and risk of hypertension through the lifecycle: do B vitamins play a role?}

Psara, E., Pentieva, K., Ward, M., \& McNulty, H. (2020). Critical review of nutrition, blood pressure and risk of hypertension through the lifecycle: do B vitamins play a role? Biochimie, 173, 76-90.

https://doi.org/10.1016/j.biochi.2020.03.016

Link to publication record in Ulster University Research Portal

\section{Published in:}

Biochimie

Publication Status:

Published (in print/issue): 30/06/2020

DOI:

10.1016/j.biochi.2020.03.016

\section{Document Version}

Author Accepted version

\section{General rights}

Copyright for the publications made accessible via Ulster University's Research Portal is retained by the author(s) and / or other copyright owners and it is a condition of accessing these publications that users recognise and abide by the legal requirements associated with these rights.

\section{Take down policy}

The Research Portal is Ulster University's institutional repository that provides access to Ulster's research outputs. Every effort has been made to ensure that content in the Research Portal does not infringe any person's rights, or applicable UK laws. If you discover content in the Research Portal that you believe breaches copyright or violates any law, please contact pure-support@ulster.ac.uk. 


\title{
Critical review of nutrition, blood pressure and risk of hypertension through the lifecycle: do B vitamins play \\ a role?
}

The corrections made in this section will be reviewed and approved by a journal production editor.

Elina Psara, Kristina Pentieva, Mary Ward, Helene McNulty ${ }^{\square}$ h.mcnulty@ulster.ac.uk

Nutrition Innovation Centre for Food and Health (NICHE), School of Biomedical Sciences, Ulster

University, Coleraine, Northern Ireland, BT52 1SA, United Kingdom

${ }^{\square}$ Corresponding author.

\begin{abstract}
Hypertension is the leading cause of preventable mortality worldwide, contributing to over 9 million deaths per annum, predominantly owing to cardiovascular disease. The association of obesity, physical inactivity and alcohol with elevated blood pressure (BP) is firmly established. Weight loss or other dietary strategies, such as the Dietary Approaches to Stop Hypertension (DASH) diet, have been shown to be effective in lowering BP. Additionally, specific nutrients are recognised to contribute to BP, with higher sodium intake linked with an increased risk of hypertension, while potassium is associated with a reduced risk of hypertension. Of note, emerging evidence has identified a novel role for one-carbon metabolism and the related B vitamins, particularly riboflavin, in BP. Specifically in adults genetically at risk of developing hypertension, owing to the common C677T polymorphism in MTHFR, supplemental riboflavin (co-factor for MTHFR) was shown in randomised trials to lower systolic BP by up to $13 \mathrm{mmHg}$. A BP response to intervention of this magnitude could have important clinical impacts, given that a reduction in systolic BP of $10 \mathrm{mmHg}$ is estimated to decrease stroke risk by $40 \%$. This review aims to explore the factors contributing to hypertension across the lifecycle and to critically evaluate the evidence supporting a role for nutrition, particularly folate-related B vitamins, in BP and risk of hypertension. In addition, gaps in our current knowledge that warrant future research in this area, will be identified.
\end{abstract}

Keywords: Blood pressure; Hypertension; Hypertension in pregnancy; One-carbon metabolism; Folate-related B vitamins

\section{Introduction}


Hypertension is recognised as the leading preventable cause of morbidity and mortality worldwide, predominantly owing to cardiovascular disease (CVD), especially stroke [1,2]. Hypertension in adults and in pregnancy is defined as a systolic/diastolic blood pressure (BP) of 140/90 $\mathrm{mmHg}$ or more at rest $[3,4]$. The relationship between BP and disease risk is continuous. In middle-aged and older individuals who have a $\mathrm{BP}>-115 / 70 \mathrm{mmHg}$, it is estimated that the risk of developing CVD doubles for every 20 and $10 \mathrm{mmHg}$ rise in systolic and diastolic BP, respectively [5]. This not only suggests that cardiovascular risk can be reduced through lowering of BP in hypertensive individuals, but that reduction in BP could also have substantial impacts in terms of CVD risk in normotensive individuals. A number of lifestyle and nutritional factors are known to influence BP throughout life and can contribute to the pathogenesis of hypertension. This review explores the factors contributing to BP variability and risk of hypertension across the lifecycle, with critical evaluation of the evidence for the role of nutrition, and in particular folate-related B vitamins, in preventing or delaying the onset of hypertension.

\section{Global burden of hypertension and hypertension in pregnancy}

Hypertension and its complications account for over 9 million deaths per annum [1]. The prevalence of hypertension worldwide rose from an estimated 600 million people in 1980 to almost 1 billion people in 2008; it is predicted to rise even further to 1.56 billion people by 2025 [6,7]. Given that hypertension is the second leading risk factor for disease burden worldwide, elevated BP is a public health concern of global proportions [2 ]. Moreover, hypertension in pregnancy may lead to serious adverse complications and outcomes. Hypertensive disorders during pregnancy carry risks for both the pregnant woman and the foetus and have been implicated in the development of one-third of severe maternal morbidity in the United Kingdom [8] and one-tenth of preterm births [9], which are the leading cause of neonatal morbidity and mortality [10]. Thus, hypertension in pregnancy, as in non-pregnancy, is of major concern.

Apart from the adverse health impacts, the financial burden associated with hypertension and hypertension in pregnancy is enormous. In the United States, the estimated direct and indirect healthcare costs for hypertension were $\$ 53.2$ billion in 2013 , whilst the direct costs of hypertension are projected to rise to a staggering \$220.9 billion by 2035 [11]. Furthermore, the costs associated with a pregnancy complicated by pre-eclampsia, a serious hypertensive disorder of pregnancy, are more than double compared to the costs associated with each case of an uncomplicated pregnancy [12]. In 2012, the total cost burden of pre-eclampsia during the first year after delivery was reported at $\$ 2.18$ billion in the United States [13].

Evidence from the National Health and Nutrition Examination Survey (NHANES) in the United States suggests that awareness of hypertension varies between different life stages with young adults (18-39 years old) being less aware of being hypertensive compared to middle aged (40-59 years) and older (60 years or older) individuals [14]. Treatment rates and BP control rates followed a similar pattern, with the older adults achieving the highest rate of BP control (54\%). A recent study of 526,336 participants showed that whilst hypertension awareness and BP control rates have substantially improved over the last few decades in the developed world [ 15], these trends have not been observed in the developing world where BP control rates are poor. The proportion of the population that is aware of their hypertensive status in developing countries is also reported to be low (3\% in Nigeria and Namibia) [16]. Furthermore, the majority of women suffering from hypertension and hypertensive disorders during pregnancy in developing countries were reported to be unaware of their condition [17-19]. Lack of awareness compromises treatment and BP control rates, which in turn can lead to an increase in the occurrence of complications associated with hypertension, such as end-organ damage and pathological 
vascular and neurological changes [3]. Thus, awareness campaigns on hypertension might benefit BP control rates by increasing the proportion of people adhering to their antihypertensive medication.

\section{Regulation, measurement and treatment of blood pressure}

Homeostasis, and hence BP control is primarily regulated by the renin-angiotensin-aldosterone system (RAAS), the baroreceptor reflex and the presence of vasoactive factors in the circulatory system [20,21]. The complex RAAS is involved in the long-term regulation of BP and essentially modulates systemic vascular resistance and the reabsorption of sodium and water which ultimately leads to a BP increase. The proteolytic renin enzyme, which is released in the blood stream by the granular cells of the juxtaglomerular apparatus in the kidney, cleaves angiotensinogen to angiotensin I. The angiotensin-converting enzyme (ACE) then facilitates the conversion of the inactive peptide angiotensin I to the active peptide angiotensin II. Angiotensin II acts directly on angiotensin type I and II receptors in the vascular system to cause vasoconstriction and thereby a BP rise. In addition, angiotensin II also stimulates the release of the steroid hormone aldosterone from the adrenal cortex to further promote sodium and water reabsorption. As a result, blood volume increases further and, therefore, BP increases $[20,21]$. Moreover, the short-term regulation of BP is mediated by the baroreceptor reflex. In response to vessel wall distention, baroreceptors, which are located on the aortic arch and carotid sinus, increase the afferent impulse activity $[20,22]$. This causes a decrease in the activity of the efferent sympathetic nervous system and an increase in the activity of the parasympathetic nervous system to augment vagal tone, stimulate bradycardia and vasodilation and eventually lower BP. As well as RAAS and the baroreceptor reflex, endothelial mechanisms are implicated in BP regulation [20]. The vascular endothelium, which constitutes the inner cellular lining of blood vessels, synthesises vasoactive factors such as nitric oxide and endothelin-1. Nitric oxide mediates vasodilation and hence, BP lowering, whilst endothelin-1 causes vasoconstriction and in turn an increase in BP. Given that $\mathrm{BP}$ is the product of cardiac output, systemic vascular resistance and arterial elasticity, an imbalance of sodium reabsorption, impaired neurogenic control, endothelial dysfunction and/or increased arterial stiffness can increase the risk of developing hypertension [20,21].

BP refers to the force exerted by blood on the walls of the large arteries in the systemic circulation. Specifically, systolic BP refers to the maximum pressure in the arteries during a contraction of the heart muscle (systole), and diastolic BP refers to the lowest pressure measured within the arteries when the heart muscle relaxes between beats (diastole) [22]. In a clinical setting, BP is predominantly measured using the auscultatory method to detect the appearance and disappearance of Korotkoff sounds in the brachial artery, which represent systolic and diastolic BP, respectively [23]. An alternative non-invasive BP monitoring method is the oscillometric technique, wherein BP is measured using an automated cuff that yields estimates of systolic and diastolic BP by the observation of oscillations in the cuff pressure [23]. Given that patients may present to the clinic with white coat hypertension (hypertensive BP levels in the clinic but not outside the clinic) or masked hypertension (hypertensive BP levels outside the clinic but not at the clinic) and that BP varies throughout the day and night, an out of office BP measurement over an extended period of time should be considered for the diagnosis of hypertension $[3,23]$. Ambulatory BP monitoring (ABPM) is the reference standard as it records BP over a 24-h period and can, therefore, track circadian rhythm and prevent false diagnosis. In the case that an ABPM is not suitable or tolerated by the patient, a home BP monitoring would be recommended to confirm the diagnosis of hypertension [3].

The main goal of antihypertensive therapy is to treat and control hypertension, and in turn, to prevent the associated complications, particularly myocardial infarction and stroke. The National Institute of Health and Care Excellence (NICE) advises that in adults under 80 years, BP should be reduced to $<140 / 90 \mathrm{mmHg}$, whereas for 
older adults over 80 years, BP should be reduced to $<150 / 90 \mathrm{mmHg}$ [3]. In women who are pregnant or planning to become pregnant, the target $\mathrm{BP}$ is $135 / 80 \mathrm{mmHg}$ [4]. In infants and children, the targets are BP $<-99^{\text {th }}$ and $95^{\text {th }}$ percentile for age, sex and height, respectively [24,25]. In hypertensive children and adolescents who have specific conditions (e.g. chronic renal disease, diabetes or hypertensive end-organ damage), it is recommended that BP be reduced to less than the $90^{\text {th }}$ percentile for age, sex and height [25]. Pharmacologic treatment of hypertension involves the use of antihypertensive agents, such as ACE inhibitors, angiotensin II receptor blockers, $\alpha$-adrenergic receptor blockers, $\beta$-blockers, calcium-channel blockers (CCBs) and diuretics; polytherapy is recommended whereby two or more antihypertensive medications are used in combination [3]. However, in pregnancy and breastfeeding, certain antihypertensive agents, such as ACE inhibitors, are contraindicated as they could be harmful to mother, foetus and offspring [4,26]. During the perinatal and antenatal periods, labetalol ( $\beta$-blocker), nifedipine (CCB) and methyldopa (centrally acting antiadrenergic) are recommended as suitable options for the treatment of hypertension [4]. Furthermore, in women who have chronic hypertension or are at high risk for pre-eclampsia, aspirin is recommended from 12 weeks of pregnancy until birth [4]. In infancy, the only antihypertensive agent proven to effectively reduce BP is captopril (ACE inhibitor) [27]. Apart from antihypertensive medications, statin therapy for the treatment of hyperlipidaemic hypertensive patients has been shown to result in a BP reduction and improved BP control rates, irrespective of antihypertensive medication [28]. Furthermore, the BP-lowering effect of statins seems to be independent of statin type or dosage administered [29]. Moreover, weight loss resulting from pharmacological (orlistat, rimonabant and topiramate) and surgical (bariatric surgery) interventions has also been shown to lead to a decrease in BP and improved BP control rates [30-34].

\subsection{Factors contributing to hypertension}

It is widely recognised that hypertension is a multifactorial condition involving the interaction of modifiable and non-modifiable risk factors.

\subsection{Modifiable risk factors for hypertension}

The link between obesity and hypertension is well documented. An estimated 15, 25 and 40\% of normal weight, overweight and obese individuals, respectively, are reported to have hypertension [35]. Excess body mass not only affects BP in the general adult population but can also have an adverse effect on BP in pregnancy and childhood. One systematic review showed that women who had a pre-pregnancy body mass index (BMI) of $\geq 30 \mathrm{~kg} / \mathrm{m}^{2}$ were up to 10 times more likely to develop gestational hypertension and pre-eclampsia [36]. Furthermore, evidence from a prospective birth cohort study in childhood showed that children who were overweight at 5 and/or 14 years of age had a higher systolic and diastolic BP at age 14 years compared to those who had a normal BMI at 5 and 14 years [37]. Therefore, controlling the global obesity epidemic for the prevention and treatment of hypertension at all life stages is of paramount importance.

It is well established that lack of regular physical activity adversely influences BP, irrespective of whether the individual is normotensive or hypertensive. One meta-analysis of 65 studies investigating the acute effects of exercise on BP showed that in the hours following an exercise session, systolic and diastolic BP were reduced by 4.8 and $3.2 \mathrm{mmHg}$ [38], respectively. Another systematic review of 27 randomised controlled trials (RCTs) in individuals with hypertension reported that regular medium-to-high intensity aerobic activity was associated with lower systolic BP by $11 \mathrm{mmHg}$ and diastolic BP by $5 \mathrm{mmHg}$ [39].

Although the evidence in relation to the effect of smoking on BP is conflicting [40], most studies report smoking as an important determinant of hypertension [41,42]. Not only is active smoking associated with an increased 
risk of incident hypertension [41], but passive smoking can also have detrimental effects on BP. Of note, Cabral et al. [42] recently reported a higher BP at 4 years of age in children whose mothers smoked prior to conception through pregnancy and childhood compared with those children of non-smoker mothers. This reinforces the importance and need of effective smoking cessation programmes and smoke-free environments from early life through older age in order to maintain more optimal BP, and thus better cardiovascular health.

Alcohol and caffeine consumption have also been associated with BP. A recent meta-analysis of 36 alcohol intervention trials with a total of 2,865 participants estimated that a reduction in alcohol consumption for at least 7 days in normotensive or hypertensive individuals who drank more than 2 drinks per day was associated with a lowering of systolic and diastolic BP by 5.5 and $4.0 \mathrm{mmHg}$, respectively [43]. Caffeine intake has also been associated with BP, but the evidence is somewhat unclear. Caffeine intakes of 200-300 mg have been shown to lead to an acute increase in systolic BP of $8.1 \mathrm{mmHg}$ and diastolic BP of $5.7 \mathrm{mmHg}$ [44], whilst the BP response to caffeine seems to be exacerbated in hypertensive patients [45]. Although the evidence on the effect of habitual consumption of caffeine on BP and hypertension risk is inconsistent [46,47], most studies indicate that regular caffeine intake does not increase BP or hypertension risk [44]. This may relate to the development of partial haemodynamic tolerance, whereby the antagonising effect of caffeine is dampened by an eventual upregulation of adenosine receptors $[44,48]$.

There is considerable evidence that certain dietary patterns and specific nutrients can strongly influence BP and potentially prevent or treat hypertension. Such evidence will be discussed in section 6 of this review.

\subsection{Non-modifiable risk factors for hypertension}

Advancing age results in structural modifications in the arteries and in particular large arterial stiffness, which in turn leads to BP changes over time [49]. Findings from the longitudinal Framingham Heart Study demonstrated that systolic BP increases linearly between the ages of 30 and 84 years, whilst diastolic BP increases until 50-60 years and then slowly declines [50]. Consequently, isolated systolic hypertension predominantly affects older adults [51]. The third NHANES in the United States showed that 3 of every 4 hypertensive adults is aged $\geq 50$ years, reiterating that advancing age is a key determinant of hypertension [52].

Sex differences in BP and risk of hypertension are also observed. The prevalence of hypertension is higher in males up to 65 years, whereas after 65 years the risk of hypertension appears to be higher in females [11,53]. It has been suggested that these sex differences in the epidemiology of hypertension might be due to a potential protective effect against hypertension development of sex hormones in women of reproductive age, which is reversed after menopause [54]. However, research investigating the effect of hormone replacement therapy on BP in postmenopausal women is controversial, indicating that the sex-related differences on BP may be more complex than initially perceived [55-57].

Racial and ethnic differences have also been shown in epidemiological studies to affect the incidence and prevalence of hypertension. A study conducted in American adults, aged 20 years or older, showed that the ageadjusted prevalence of hypertension in Asians, Hispanics, Whites and Blacks was 27.0, 29.0, 29.2 and 42.4\%, respectively [53]. The same study also showed that, compared to Hispanic adults, the life expectancy of Black Americans was shorter by 7 years, possibly owing to higher rates of hypertension. Given that the difference in BP observed between Blacks and Whites was shown to begin at 15 years of age and that BP tracks with age, interventions to prevent hypertension in this at-risk population should ideally be commenced in adolescence [58]. 
There is strong evidence suggesting that an estimated $48-60 \%$ of systolic and $34-67 \%$ of diastolic BP variance may be attributed to heritability $[59,60]$. The prevalence of hypertension was shown to be significantly higher in individuals who have family history of hypertension compared to those without [61]. In addition, BP levels amongst normotensive individuals were also found to be higher in those with a positive family history [62]. Furthermore, Ness et al. [63] demonstrated that the risk of developing hypertension in pregnancy and preeclampsia in women who had at least two first-degree family members with hypertension was twofold higher than those who had no family history. Thus, BP should be closely monitored in individuals with a family history of hypertension, even when BP is normal.

\section{Blood pressure and risk of hypertension through the lifecycle}

\subsection{Pregnancy}

Multiple physiological changes occur during pregnancy, leading to an initial decrease in BP until the $20^{\text {th }}$ gestational week, followed by a progressive increase until term [64-66]. Hypertension is not only a risk factor in the general population but is of particular concern in pregnant women, with up to $15 \%$ of pregnancies complicated by hypertension [67]. In such pregnancies, the BP pattern deviates from the typical one. A recent meta-analysis by de Haas et al. [68] showed that the mid-gestational systolic BP drop is absent in hypertensive pregnancies, while diastolic BP initially decreases and after mid-pregnancy both systolic and diastolic BP rise to higher levels and in a steeper slope than in normotensive pregnancies.

Hypertension in pregnancy can be defined as i) chronic hypertension, ii) gestational hypertension or iii) preeclampsia [4]. Chronic hypertension refers to pre-existing hypertension or hypertension diagnosed before the $20^{\text {th }}$ week of gestation, whereas gestational hypertension is defined as high BP occurring for the first time after the $20^{\text {th }}$ week of gestation. Gestational hypertension usually resolves postpartum, however, if high BP persists beyond the $12^{\text {th }}$ week after pregnancy, then the diagnosis of chronic hypertension can be assigned [69]. Preeclampsia is a condition unique to human pregnancy and is characterised by the presence of hypertension and proteinuria or hypertension and end-organ dysfunction with or without proteinuria [4]. The occurrence of seizures in combination with the pre-eclamptic phenotype leads to the diagnosis of eclampsia.

The prevalence of hypertension and pre-eclampsia has increased in the recent years, possibly due at least in part to advanced maternal age and the obesity epidemic [70,71]. Chronic hypertension, gestational hypertension and pre-eclampsia or eclampsia complicate $1-5 \%, 6-7 \%$ and up to $5-7 \%$ of all pregnancies, respectively [72]. Compared to women who had normotensive pregnancies, women with a history of hypertension in pregnancy are at an increased risk for hypertension and stroke in later life [69]. Furthermore, women with a history of hypertensive disorder of pregnancy are typically diagnosed with hypertension on average 8 years earlier than those with no such history [73]. This suggests that hypertension in pregnancy not only influences pregnancy outcomes, but also increases the risk of hypertension and age of onset of hypertension in later life.

\subsection{Infancy}

Defining normal BP in infants, especially neonates, is extremely complex as BP and the pattern of BP at this stage of life are strongly correlated with birth weight, size, gestational age, chronological age and postmenstrual age (i.e. gestational age plus chronological age) [74-76]. BP of term newborns remains unchanged in the first 15 minutesfifteen minutes after birth, whereas BP of newborns who were born preterm decreases steadily within the first 3 hoursthree hours of life [77,78]. Eventually, BP spontaneously rises during the first 5-7 days in neonates, after which point the rise in $\mathrm{BP}$ is less rapid $[75,79,80]$. It has also been reported that the rate of 
increase in systolic BP during infancy is greater than the rate of increase in diastolic BP [81]. Moreover, the BP rise in preterm newborns is reported to be more pronounced than in term newborns [79,82]. However, after 14 days of life, BP in preterm neonates appears to stabilise and is found to be similar to that of term infants [82].

Hypertension in infants aged 1 month to 1 year is defined as a BP $\geq-95^{\text {th }}$ percentile for age, sex, height and weight [74], whereas hypertension in neonates is defined as a systolic BP greater or equal to the $95^{\text {th }}$ percentile for chronological age, postmenstrual age, sex, birth weight and appropriateness of size for age [24,74]. Although $5 \%$ of infants are hypertensive by definition, the reported incidence of infantile hypertension ranges from $0.2 \%$ in healthy newborns, to $3.0 \%$ in the neonatal intensive care unit $[74,83]$.

\subsection{Childhood and adolescence}

In children, BP increases progressively and is similar between the two sexes before puberty. The upward trend in BP continues during adolescence, albeit the incline is steeper. In particular, males experience a more marked pubertal rise than females and the widely accepted sex-related differences in BP are slowly established [84]. The prevalence of hypertension and pre-hypertension in British children and adolescents was estimated at 2.3 and $6.9 \%$, respectively, in 2007 [84].

In the United Kingdom, hypertension in children and adolescents is defined as a BP above the $98^{\text {th }}$ percentile for age [84]. Hypertension in childhood and adolescence is becoming a major concern as a strong association has been established of paediatric hypertension and pre-hypertension with hypertension and CVD risk in adulthood [ 85,86]. An estimated 1 in every 2 hypertensive adults had elevated BP in childhood [87]. As in adulthood, paediatric hypertension may also result in irreversible end-organ and vascular damage $[88,89]$. The collated evidence suggests that BP monitoring in children and adolescents is important, but in practice, BP is likely to be overlooked in most paediatric settings. Despite having their BP measured and recorded, three quarters of all hypertensive and pre-hypertensive paediatric patients remain undiagnosed [90].

\subsection{Adulthood}

Systolic and diastolic BP continuously increase from early adulthood to middle-age with a systolic/diastolic BP of $<120 / 80 \mathrm{mmHg}$ considered as normal BP, since it is associated with the lowest CVD risk and related adverse outcomes [51]. The prevalence of hypertension in adults aged 18-39 years and 40-59 years is reported to be 7.3 and $32.7 \%$, respectively [14]. Of note, normotensive individuals at age 55 are reported to have a $90 \%$ lifetime risk of developing hypertension [91]. In addition, individuals who experience a reduction or no change in BP by the age of 55 have the lowest lifetime risk for CVD (22-41\%), compared to those who had or developed hypertension by that age (42-69\%) [92]. Thus, primary prevention of hypertension is crucial to alleviate a potential public health burden. It is extensively documented that the use and duration of use of hormonal contraceptives (the most widely used method of birth control by women) are associated with increased BP and risk of hypertension [93]. However, cessation of hormonal contraceptives eventually cancels the excess hypertension risk and restores BP to baseline levels [94]. Hence, the BP of women who are taking hormonal contraceptives should be regularly monitored and if needed, an alternative method of birth control considered.

In adults aged 18-39 years, BP within the normal range is associated with a reduced risk of heart failure compared with a systolic or diastolic BP of $130 \mathrm{mmHg}$ or $80 \mathrm{mmHg}$ or more, respectively [95]. These cardiovascular outcomes are thought to be a result of pathological changes in the heart and the vasculature, which are caused by elevated BP. Recently, three-dimensional echocardiography revealed that, even after adjusting for relevant confounders, higher cumulative BP from early adulthood to middle age is linked to left 
atrial remodelling and dysfunction [96]. Additionally, findings from the 'Insight 46' epidemiological study of dementia-free individuals showed that high BP in midlife is associated with increased white matter hyperintensity volume and smaller whole-brain volume at 70 years of age, suggesting that BP within this age group is a predictor for potential adverse outcomes in later life [97].

\subsection{Older age}

Systolic BP is known to increase with age throughout life whereas diastolic BP increases until about 60 years and then declines [98]. Evidence from the United States showed that two thirds of adults (60 years or older) were hypertensive [14]. Interestingly, recent results from a population-based cohort study of older participants over a 20-year period revealed that both systolic and diastolic BP decline during the 18 to 14 years before death; $64 \%$ of these individuals experienced a reduction in systolic BP of greater than $10 \mathrm{mmHg}$ [99]. In line with the findings of Ravindrarajah et al. [100], the decline in BP was shown to be accelerated in the last two years of life [99].

$\mathrm{BP}$ reduction and control in older age remain important for the prevention of CVD [5,101]. Evidence shows that standard BP control (systolic BP of $<140 \mathrm{mmHg}$ ) in older hypertensive patients led to a reduction of cardiovascular events as expected [102]. Of note, the Systolic BP Intervention Trial (SPRINT) showed that compared to standard BP treatment, intensive BP treatment (BP target of $<120 \mathrm{mmHg}$ ) in older adults with hypertension resulted in lower death rates from CVD (by 43\%) and any cause (by 27\%) [103]. In contrast to the beneficial effects of intensive treatment reported in the SPRINT trial, another study found that older, treated hypertensives with a systolic BP of $<135 \mathrm{mmHg}$ and $125 \mathrm{mmHg}$ were at increased risk of mortality and incident heart failure, respectively [104]. Thus, the issue of BP management in older adults is somewhat controversial. Also, use of antihypertensives and low BP in older adults have been linked with increased risk for serious fall injuries in some studies [105,106], whilst other studies show no such associations [107]. Apart from the importance of effective BP management for cardiovascular health and mortality, BP plays a key role in cognitive function and brain health. A systolic BP of $\geq 130 \mathrm{mmHg}$ in treated hypertensive patients aged 75 years or older was associated with less cognitive decline after 1 year [108]. Collectively, the evidence suggests that BP in older age should be regularly monitored and tightly regulated in order to maintain health and wellness.

\section{Nutrition interventions to lower blood pressure}

\subsection{Energy intake and obesity}

Body weight, weight gain and obesity are strongly associated with BP [35,109]. Thus, lifestyle modifications to induce weight reduction is the first line of treatment in pre-hypertensive and hypertensive patients [3,4,25], with reports estimating that for every $10 \mathrm{~kg}$ of weight loss, systolic BP potentially decreases by an estimated 5$20 \mathrm{mmHg}$ [51]. However, weight loss of this magnitude is extremely difficult to achieve in practice for both health professionals and patients, and even harder to sustain in the longer term. Of note, the Look AHEAD (Action for Health in Diabetes) study, a multicentred RCT of 5,145 overweight or obese individuals with type 2 diabetes, tested the effectiveness of two approaches to weight loss over one year [110]. One approach was an intensive lifestyle intervention involving a programme of behavioural modifications for weight management, a diet plan with caloric restriction and increased physical activity. The other approach was 'usual care', comprising of a programme of diabetes support and education. After one year of follow-up, the percentage of initial body weight loss was greater in those assigned to the intensive lifestyle intervention (8.6\%) compared with those assigned to receive usual care $(0.7 \%)$. Furthermore, the weight loss achieved by the intensive lifestyle intervention group led to greater reductions in systolic/diastolic BP (-_6.8/-3.0 $\mathrm{mmHg})$ compared to the usual 
care group (--2.8/-1.8 $\mathrm{mmHg}$ ) and prevented the increase in antihypertensive medication users at one year (-- $0.1 \%$ vs $2.2 \%)$.

\subsection{Dietary patterns}

Emerging evidence has identified certain dietary patterns to be linked with BP across all age groups, most notably, the Dietary Approaches to Stop Hypertension (DASH) diet, which is characterised by a high consumption of fruits, vegetables, whole grains and low-fat dairy and a reduced consumption of saturated and total fat (Table 1). In comparison to a control typical 'American' diet, comprised of low fruit, vegetable and dairy product consumption and high consumption of saturated and total fat, the DASH diet was shown to be highly effective in reducing systolic/diastolic BP among normotensive (by 3.5/2.1 $\mathrm{mmHg}$ ) and hypertensive individuals (by $11.4 / 5.5 \mathrm{mmHg}$ ) after 8 weeks of intervention [111]. Of interest, the effect of the DASH diet on BP was found to be maintained at 8 months after completion of the trial [112]. Moreover, the DASH diet is not only effective in non-pregnant adults, but it has also been shown to have a BP-lowering effect in pregnant women and adolescents [113-115]. The effects of the DASH diet on BP may be at least partly explained by dairy-rich nutrients including calcium, as the recently published INTERnational study on MAcro/micronutrients and blood Pressure (INTERMAP) confirmed that low-fat dairy consumption was associated with lower BP in 2,694 participants aged 40-59 years [116]. Unsurprisingly, modifications to the DASH diet to reduce sodium intake or body weight have been shown to further lower BP compared to the DASH diet alone $[112,117,118]$. Taken together, this evidence supports the implementation of the DASH diet or its modified versions as an effective lifestyle intervention for the prevention, and potentially the treatment, of hypertension through the lifecycle.

alt-text: Table 1

Table 1

Effectiveness of selected nutritional interventions to lower systolic blood pressure.

\begin{tabular}{|c|c|c|c|c|}
\hline Author & Population & Cohort & Intervention & Main findings \\
\hline \multicolumn{5}{|c|}{ Dietary patterns } \\
\hline $\begin{array}{l}\text { Appel et } \\
\text { al. [111] } \\
1997\end{array}$ & $\begin{array}{l}\text { United } \\
\text { States }\end{array}$ & $\begin{array}{l}n=459 \\
44-45 \text { years } \\
\text { (Pre)hypertensive }\end{array}$ & $\begin{array}{l}\text { 8-week intervention } \\
\text { with the 'DASH' diet vs } \\
\text { a diet rich in fruits and } \\
\text { vegetables only vs a } \\
\text { control diet } \\
\text { DASH diet: rich in } \\
\text { fruits, vegetables, whole } \\
\text { grains and low-fat dairy } \\
\text { and low saturated and } \\
\text { total fat } \\
\text { Control 'American' diet: } \\
\text { low in fruits, vegetables } \\
\text { and dairy products and }\end{array}$ & $\begin{array}{l}\text { Compared with the control diet, the DASH diet } \\
\text { lowered systolic BP by } 5.5 \mathrm{mmHg} \text { overall, by } \\
3.5 \mathrm{mmHg} \text { in normotensives and by } \\
11.4 \mathrm{mmHg} \text { in hypertensives. The BP-lowering } \\
\text { effect of the DASH diet was greater than that of } \\
\text { the diet rich in fruits and vegetables only }\end{array}$ \\
\hline
\end{tabular}

The table layout displayed in this section is not how it will appear in the final version. The representation below is solely purposed for providing corrections to the table. To preview the actual presentation of the table, please view the Proof. 
high in saturated and

total fat

A 3-month intervention

with a 'Mediterranean'

diet with virgin olive oil

(1 L/week) vs a

Mediterranean diet with

nuts (30 g/day) vs a low-

fat diet

Mediterranean diet:

high in olive oil, nuts,

fruits and vegetables,

and low in red meat and

processed foods
Compared with the low-fat control diet, systolic BP decreased in response to the Mediterranean diet with olive oil by $5.9 \mathrm{mmHg}$ and the Mediterranean diet with nuts by

$7.1 \mathrm{mmHg}$

\section{Specific nutrients}

\begin{tabular}{|c|c|c|c|c|}
\hline $\begin{array}{l}\text { Gu et al. [ } \\
200] \\
2001\end{array}$ & China & $\begin{array}{l}n=150 \\
56.9 \text { years } \\
\text { (Pre)hypertension }\end{array}$ & $\begin{array}{l}\text { 12-week RCT with } \\
\text { potassium chloride } \\
\text { ( } 60 \mathrm{mmol} / \text { day) vs } \\
\text { placebo }\end{array}$ & $\begin{array}{l}\text { Potassium chloride supplementation lowered } \\
\text { systolic BP by } 5.0 \mathrm{mmHg}\end{array}$ \\
\hline $\begin{array}{l}\text { He et al. [ } \\
201] \\
2009\end{array}$ & Europe & $\begin{array}{l}n=338 \\
50 \text { years } \\
\text { Untreated } \\
\text { hypertensive }\end{array}$ & $\begin{array}{l}\text { A } 2 \text {-week reduced-salt } \\
\text { diet followed by the } \\
\text { addition of slow sodium } \\
\text { (90 mmol/day) vs } \\
\text { placebo; 6-week } \\
\text { crossover RCT }\end{array}$ & $\begin{array}{l}\text { Reduction in salt intake lowered systolic BP } \\
\text { by } 5.0 \mathrm{mmHg}\end{array}$ \\
\hline $\begin{array}{l}\text { Forman et } \\
\text { al. }[150] \\
2013\end{array}$ & $\begin{array}{l}\text { United } \\
\text { States }\end{array}$ & $\begin{array}{l}n=283 \\
51 \text { years } \\
\text { Predominantly } \\
\text { normotensive }\end{array}$ & $\begin{array}{l}\text { 3-month RCT during } \\
\text { winter time with } 1000 \text {, } \\
2000 \text { or } 4000 \mathrm{IU} / \text { day } \\
\text { cholecalciferol vs } \\
\text { placebo }\end{array}$ & $\begin{array}{l}\text { A dose-response relationship of cholecalciferol } \\
\text { supplementation and systolic BP was shown, } \\
\text { with a BP-lowering response up to } 4.0 \mathrm{mmHg}\end{array}$ \\
\hline
\end{tabular}

\section{$B$ vitamins}

\begin{tabular}{|c|c|c|c|c|}
\hline $\begin{array}{l}\text { Van Dijk } \\
\text { et al. [190 } \\
\text { ] } \\
2001\end{array}$ & Europe & $\begin{array}{l}n=130 \\
45-46 \text { years } \\
\text { Siblings of } \\
\text { patients with } \\
\text { premature } \\
\text { atherothrombosis }\end{array}$ & $\begin{array}{l}\text { 2-year RCT with FA } \\
(5 \mathrm{mg} / \text { day) plus } \\
\text { pyridoxine } \\
(250 \mathrm{mg} / \text { day) vs placebo }\end{array}$ & $\begin{array}{l}\text { B vitamin intervention lowered systolic BP by } \\
3.7 \mathrm{mmHg}\end{array}$ \\
\hline $\begin{array}{l}\text { Toole et } \\
\text { al. [188] } \\
2004\end{array}$ & $\begin{array}{l}\text { United } \\
\text { States, } \\
\text { Canada, } \\
\text { Europe }\end{array}$ & $\begin{array}{l}n=3,649 \\
66 \text { years } \\
\text { Cerebral infarct }\end{array}$ & $\begin{array}{l}\text { 2-year RCT with high } \\
\text { dose combined FA } \\
(2.5 \mathrm{mg}) \text {, pyridoxine } \\
(25 \mathrm{mg}) \text { and cobalamin } \\
(0.4 \mathrm{mg}) \text { vs negligible } \\
\text { dose }\end{array}$ & $B$ vitamin intervention did not affect $B P$ \\
\hline $\begin{array}{l}\text { McMahon } \\
\text { et al. [189 } \\
\text { ] } \\
2007\end{array}$ & $\begin{array}{l}\text { New } \\
\text { Zealand }\end{array}$ & $\begin{array}{l}n=249 \\
73-74 \text { years } \\
\text { Elevated } \\
\text { homocysteine }\end{array}$ & $\begin{array}{l}\text { 2-year RCT with } \\
\text { combined L-5- } \\
\text { methylTHF }(1 \mathrm{mg}) \text {, } \\
\text { vitamin B12 }(500 \mu \mathrm{g})\end{array}$ & $\mathrm{B}$ vitamin intervention did not affect $\mathrm{BP}$ \\
\hline
\end{tabular}


and vitamin B6 (10 mg)

vs placebo

5-year RCT with FA

$(0.8 \mathrm{mg} /$ day $)$ in

combination with

enalapril (10 mg/day) vs

enalapril (10 mg/day)

alone
No difference in systolic BP response between

FA combined with enalapril $(-27.1 \mathrm{mmHg})$ and enalapril alone (-27.1 mmHg). However, FA reduced the risk of first stroke by $21 \%$

B vitamins in MTHFR genotype stratified groups

\begin{tabular}{|c|c|c|c|c|}
\hline $\begin{array}{l}\text { Horigan et } \\
\text { al. [185] } \\
2010\end{array}$ & Europe & $\begin{array}{l}n=197 \\
53-54 \text { years } \\
\text { Hypertensive } \\
\text { with CVD }\end{array}$ & $\begin{array}{l}16 \text {-week RCT with } \\
\text { riboflavin }(1.6 \mathrm{mg} / \text { day }) \\
\text { vs placebo }\end{array}$ & $\begin{array}{l}\text { Riboflavin lowered systolic BP by } 13.4 \mathrm{mmHg} \text {, } \\
\text { specifically in those with the MTHFR } 677 \mathrm{TT} \\
\text { genotype. No BP response in CC or CT } \\
\text { genotypes }\end{array}$ \\
\hline $\begin{array}{l}\text { Wilson et } \\
\text { al. [186] } \\
2012\end{array}$ & Europe & $\begin{array}{l}n=62 \\
58.2 \text { years } \\
\text { Hypertensive } \\
\text { with CVD and } \\
\text { the TT genotype }\end{array}$ & $\begin{array}{l}\text { 16-week crossover trial } \\
\text { with riboflavin } \\
(1.6 \mathrm{mg} / \text { day }) \text { vs placebo }\end{array}$ & Riboflavin lowered systolic BP by $9.2 \mathrm{mmHg}$ \\
\hline $\begin{array}{l}\text { Wilson et } \\
\text { al. [187] } \\
2013\end{array}$ & Europe & $\begin{array}{l}n=91 \\
69.1 \text { years } \\
\text { Hypertensive } \\
\text { without CVD, but } \\
\text { with the TT } \\
\text { genotype }\end{array}$ & $\begin{array}{l}16 \text {-week RCT with } \\
\text { riboflavin }(1.6 \mathrm{mg} / \text { day }) \\
\text { vs placebo }\end{array}$ & $\begin{array}{l}\text { Riboflavin lowered systolic BP by } 5.6 \mathrm{mmHg} \text {. } \\
\text { BP control rates increased from } 32 \% \text { to } 57 \% \text { in } \\
\text { response to riboflavin supplementation }\end{array}$ \\
\hline
\end{tabular}

Abbreviations: DASH, Dietary Approaches to Stop Hypertension; BP, blood pressure; CVD, cardiovascular disease; RCT, randomised controlled trial; FA, folic acid; THF, tetrahydrofolate; MTHFR, methylenetetrahydrofolate reductase.

Apart from the DASH diet, other dietary patterns or foods have been linked with improved BP and cardiovascular health. The 'Mediterranean' diet, which includes high intakes of extra virgin olive oil, nuts, fruits, vegetables, and minimal intakes of red meat and processed foods [119], has been the subject of a number of studies. The Prevención con Dieta Mediterránea (PREDIMED) randomised trial reported on the effects of this dietary pattern in older adults at high cardiovascular risk [120]. Compared to a low-fat control diet, the Mediterranean diet with extra virgin olive oil or with nuts resulted in significant reductions in systolic BP of 5.9 and $7.1 \mathrm{mmHg}$, respectively, at 3 months [120]. Although the mechanism explaining the BP-lowering effect of the Mediterranean diet is unclear, it may be mediated by the typically high polyphenol content of this dietary pattern. Dietary polyphenols are associated with an increase in the endothelial production of nitric oxide which, in turn, stimulates vasodilation and hence mediates a reduction in BP [121]. Although there is evidence of the beneficial effects of the Mediterranean diet on BP, data on the prevention and treatment of hypertension with this dietary pattern are not conclusive [122]. Accumulating evidence also indicates that increased fruit and vegetable consumption is inversely associated with hypertension and CVD [123]. Of interest, a crossover RCT investigating the acute BP effect of beetroot juice (with four doses of either 0, 100, 250 and $500 \mathrm{~g}$ ) showed that BP was significantly reduced over the 24-h post-ingestion period, in a near dose-response manner [124]. The mechanism by which beetroot juice reduces BP may be mediated through the nitric oxide pathway [125]. Nitrates, which are abundantly found in beetroot juice, are reduced to nitrites by the microbiome in the oral cavity. Endothelial nitric oxide synthase (eNOS) further reduces nitrites to nitric oxide and stimulates relaxation of the vascular smooth muscle, thus leading to a reduction in BP [125]. 


\subsection{Specific nutrients}

A meta-analysis of 34 randomised trials (3,230 participants) showed that a reduction of $4.4 \mathrm{~g}$ in daily salt intake for at least four weeks resulted to a decline of $4.2 \mathrm{mmHg}$ in systolic BP and $2.1 \mathrm{mmHg}$ in diastolic BP [126]. Given that the current average dietary salt intake is estimated to be 9-12 g/day [127], a reduction of at least $4.4 \mathrm{~g}$ in daily salt intake to comply to the World Health Organisation's target of less than $5 \mathrm{~g} /$ day [128], could have major beneficial impact on cardiovascular and public health. In fact, a modest decrease of $2 \mathrm{mmHg}$ in diastolic $\mathrm{BP}$ at a population level (potentially achievable via a reduced salt intake) could be predicted to result in 17, 6 and $15 \%$ reduction in hypertension prevalence, coronary heart disease risk and stroke risk, respectively [129]. A recently published meta-analysis of 133 randomised trials including 12,197 participants showed a dose-response relationship of sodium reduction with BP, whereby each $50 \mathrm{mmol}$ reduction in 24-h sodium excretion (i.e. the best measure of salt intake) was associated with a decrease in systolic and diastolic BP of 1.10 and $0.33 \mathrm{mmHg}$, respectively [130]. However, evidence suggests that the effect of sodium intake on BP varies greatly between individuals since the BP of some individuals rises after sodium loading, whilst the BP remains unaffected in others $[131,132]$. In those who do experience a BP change with reduced sodium intake or sodium loading, the diagnosis of 'sodium sensitivity' can be assigned [131]. Furthermore, sodium sensitivity has been shown to exist in normotensives as well as those with hypertension, albeit with a higher prevalence among the latter $[131,132]$. However, currently there is no agreement on the characterisation of the sodium sensitive individuals $[133,134]$.

BP responses to potassium have been examined in numerous observational and interventional studies. A metaanalysis of 22 RCTs and 11 cohort studies in adults by Aburto et al. [135] showed an inverse association of potassium intake with $\mathrm{BP}$ and stroke, though a dose-response relationship was absent. Additionally, the most marked systolic BP reduction $(7.2 \mathrm{mmHg})$ was exhibited when potassium intake was 90-120 mmol/day [135]. Furthermore, observational studies in pregnancy found serum potassium to be significantly lower in hypertensive pregnancies than in normotensive pregnancies [136].

Calcium supplementation (1 g/day) has been shown to reduce BP in most, but not all studies [137-139]. Moreover, calcium supplementation during pregnancy resulted in lower maternal BP, lower risk of pre-eclampsia and lower offspring BP in the early years of life [140-142]. These findings suggest that, apart from a potential role in the treatment of hypertension, calcium may have a role in maintaining healthy BP from in utero to older age.

Magnesium is another nutritional factor that may influence BP. A meta-analysis of 34 randomised trials involving 2,028 individuals demonstrated very small, but significant, BP reductions with magnesium supplementation [143 ]. Interestingly, co-administration of magnesium with antihypertensive medication has been shown to have an additive effect on BP reductions compared to antihypertensive medication alone. Hence, magnesium therapy for hypertension could lead to improved BP control in hypertensive patients [144].

A protective role of polyphenols in CVD and hypertension has been suggested $[145,146]$. An RCT using a diet with either polyphenol-rich olive oil ( $\sim 30 \mathrm{mg} /$ day) or polyphenol-free olive oil in young women with prehypertension and mild hypertension demonstrated a notable decrease in systolic and diastolic BP of 7.9 and $6.7 \mathrm{mmHg}$, respectively, in response to the polyphenol intervention [147]. Furthermore, recent findings have shown that the effect of polyphenols on BP might be sex specific and confined to certain polyphenol classes and subclasses [148,149].

The role of vitamin D in bone health and calcium metabolism is well established, whereas its effect on BP and hypertension remains unclear. A 3-month RCT with placebo or 1000, 2000 or 4000 international units of 
vitamin D3 per day showed that vitamin D3 supplementation had no effect on diastolic BP, whilst systolic BP was significantly reduced in a dose-response manner [150]. In contrast, a recent systematic review and metaanalysis of randomised trials (1,687 participants) showed that BP remained unchanged in response to vitamin D3 supplementation in vitamin D deficient adults [151]. Therefore, the role of vitamin D supplementation in BP is unclear.

\section{One-carbon metabolism, related $B$ vitamins and blood pressure}

\subsection{Role of B vitamins within one-carbon metabolism}

Tetrahydrofolate (THF)-mediated one-carbon metabolism encompasses a complex network of interdependent pathways that support a variety of processes, including purine and thymidine biosynthesis, amino acid homeostasis and epigenetic mechanisms (Fig. 1). Biologically active folates are present as reduced co-factor forms, i.e. THF, with the predominant form in plasma and cells carrying a methyl group, i.e. 5-methylTHF (5MTHF). Folic acid, the synthetic form of folate, has to be sequentially reduced to form dihydrofolate and then THF via dihydrofolate reductase. THF then enters the folate cycle and the pyridoxal 5'-phosphate (PLP; active form of vitamin B6)-dependent conversion of serine to glycine donates a methyl group to THF to form 5, 10methyleneTHF, which is then converted to 5-MTHF [152]. Riboflavin (vitamin B2) is also involved in onecarbon metabolism in one of two co-factor forms, flavin mononucleotide (FMN) and flavin adenine dinucleotide (FAD) [153]. FMN is required by pyridoxine-phosphate oxidase to biologically convert most naturally available vitamin B6 to the active co-factor form PLP in tissues, whereas FAD is required as a co-factor for the key folatemetabolising enzyme, methylenetetrahydrofolate reductase (MTHFR) [152,153]. The flavoprotein MTHFR catalyses the conversion of 5,10-methyleneTHF to 5-MTHF which then serves as a methyl donor for the regeneration of methionine from homocysteine [152]. The reaction responsible for homocysteine remethylation and consequent THF regeneration links the folate cycle with the methionine cycle and is catalysed by the methylcobalamin (vitamin B12)-dependent methionine synthase. Remethylation of homocysteine to methionine is of particular importance as methionine and adenosine triphosphate act as the substrates for Sadenosylmethionine synthetase to form S-adenosylmethionine; the universal methyl donor which plays a key role in epigenetics, biosynthetic processes and in sulphur metabolism [152].

alt-text: Fig. 1

Fig. 1 


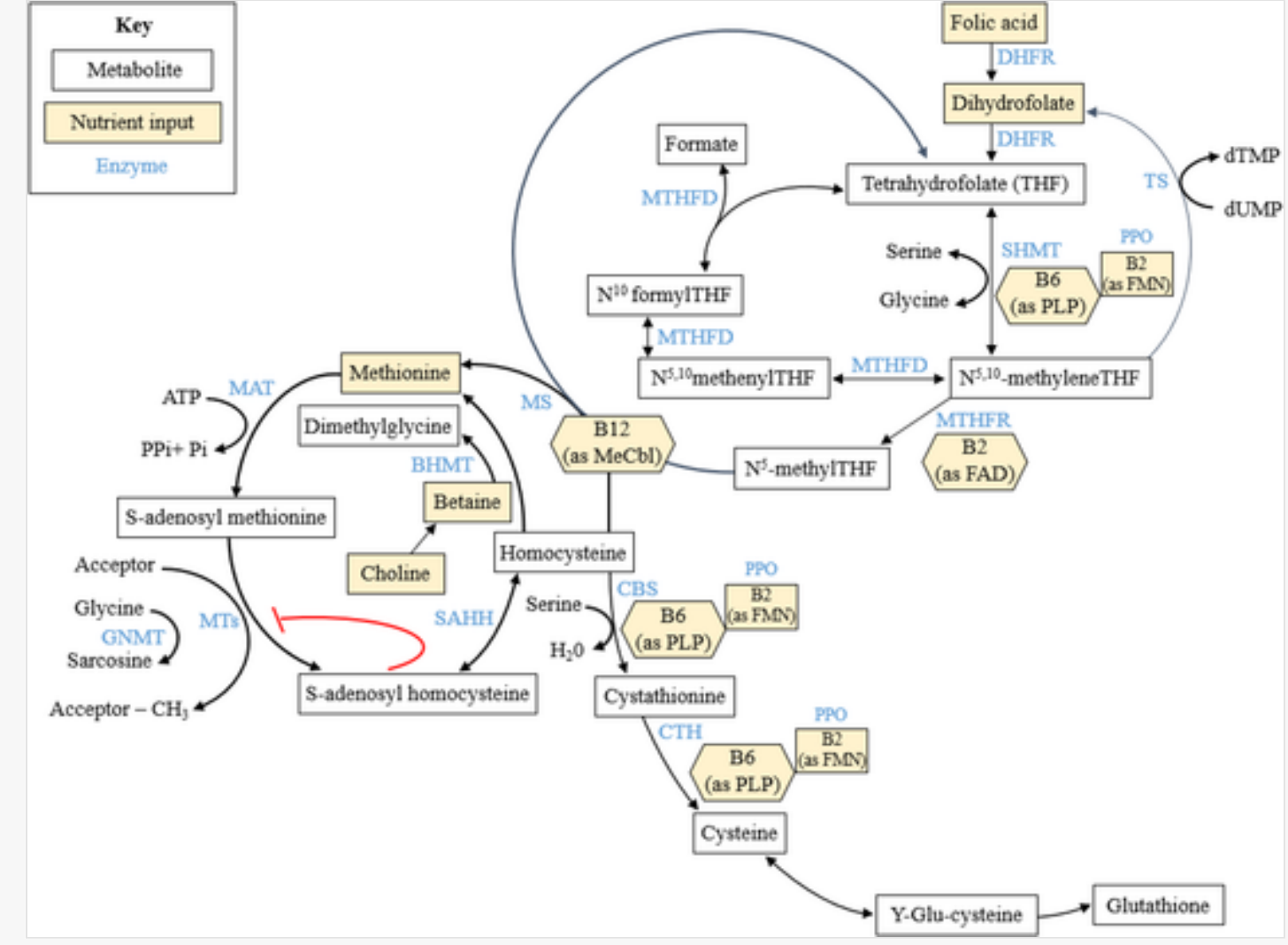

(Colour online and in press) B vitamins and one-carbon metabolism. B2, vitamin B2 (riboflavin); B6, vitamin B6; B12, vitamin B12; BHMT, betaine-homocysteine methyltransferase; CBS, cystathionine $\beta$-synthase; CTH, cystathionine $\gamma$-lyase; DHFR, dihydrofolate reductase; dTMP, deoxythymidine monophosphate; dUMP, deoxyuridine monophosphate; FAD, flavin adenine dinucleotide; FMN, flavin mononucleotide; GNMT, glycine N-methyltransferase; MAT, methionine adenosyltransferase; MeCbl, methylcobalamin; MS, methionine synthase; MT, methyltransferases; MTHFR, methylenetetrahydrofolate reductase; MTHFD, methylenetetrahydrofolate dehydrogenase; PLP, pyridoxal 5'-phosphate; PPO, pyridoxine-phosphate oxidase; SAHH, S-adenosylhomocysteine hydrolase; SHMT, serine hydroxymethyltransferase; TS, thymidylate synthase. (For interpretation of the references to colour in this figure legend, the reader is referred to the Web version of this article.)

\subsection{One-carbon metabolism in relation to adverse pregnancy outcomes and cardiovascular} disease

One-carbon metabolism requires an adequate supply of folate, along with vitamin B12, vitamin B6 and riboflavin. Sub-optimal status of any of these B vitamins and/or genetic polymorphisms on B vitamin-dependent enzymes in one-carbon metabolism, can result in a disruption of one-carbon metabolic pathways which can lead to adverse phenotypes, even if dietary folate and related B vitamin intakes are adequate $[154,155]$. 
Folate is of particular importance in pregnancy and foetal development owing to its essential role in cell division and tissue growth. The role of periconceptional maternal folate in the prevention of neural tube defects is widely recognised, however, folate has a number of other roles throughout pregnancy with important impacts for maternal and offspring health [156]. Supplementation with folic acid has been shown to prevent the decline in maternal folate concentrations that typically occurs during pregnancy [157] and hence, prevent the occurrence of megaloblastic anaemia of pregnancy [158]. Given that the regeneration of methionine from homocysteine is dependent on folate, a low folate status leads to elevated homocysteine concentrations, a phenotype that can be alleviated in response to intervention with folic acid alone or in combination with related B vitamins [159].

There is extensive evidence to link low folate status (and/or elevated homocysteine concentrations) with an increased risk of adverse pregnancy complications and outcomes including gestational hypertension [160], preeclampsia [161-163], placental abruption [164], pregnancy loss [165,166], low birth weight and intrauterine growth restriction [167]. The risk of gestational hypertension and pre-eclampsia was shown in some studies to be reduced by folic acid supplementation during pregnancy [160], albeit the evidence is somewhat conflicting [168 ]. Of note, recent evidence from an RCT with high dose folic acid beyond the first trimester of pregnancy showed that folic acid had no beneficial effect on pre-eclampsia in women at high risk for this condition [168]. Such inconsistencies might be explained by intra- and inter-population genetic variation and/or differences in nutritional status of folate and related B vitamins. Of interest, genome-wide association studies (GWAS) and epidemiological studies have linked the common MTHFR C677T polymorphism with hypertension and hypertension in pregnancy [155,169-171]. The role of this polymorphism in BP will be discussed further in section 7.3.

Considerable evidence links one-carbon metabolism with CVD, especially stroke [172]. Most notably, findings from the 5-year China Stroke Primary Prevention Trial (CSPPT) of 20,702 hypertensive patients showed that intervention with folic acid resulted in no BP-lowering effect, but significantly reduced the incidence of first stroke by 21\% (Table 1) [173]. Of note, the MTHFR C677T polymorphism has been linked with several adverse health outcomes, including an increased CVD risk by up to 40\% [172]. Less well recognised is evidence showing that the MTHFR C677T polymorphism is associated with an increased risk of hypertension and hypertension in pregnancy by up to $87 \%$ [169,174-177].

Most relevant studies examining adverse pregnancy and CVD outcomes in relation to folate have focused on plasma homocysteine as the relevant risk factor, but it is likely that folate and metabolically related B vitamins have protective roles against disease that are independent of their homocysteine-lowering effects [178].

\subsection{One-carbon metabolism, MTHFR and blood pressure}

The frequency of the MTHFR 677-TT genotype is $10 \%$ worldwide, however, the distribution varies according to geographical area, in that it ranges 0-3\% (in Africa), 8-11\% (in Australia), 3-18\% (in United States), $8-20 \%$ (in China) and 4-26\% (in Europe) [179]. The highest reported frequency of the TT genotype is in Mexico (32\%) [179]. In addition, geographical gradients in MTHFR genotype frequencies in Europe (north to south increase) and China (south to north increase) have been reported [179,180]. As well as geographical variations, ethnicity also appears to influence the frequencies of MTHFR genotypes; populations of African, European and American Hispanic ancestry have a low, intermediate and high TT genotype distribution, respectively [179]. Notably, in Mexico, the TT genotype has been shown to be as high as 44\% in Mexican Amerindians [181]. Collectively, these findings confirm the impact of ethnogeographic variations in the frequency and distribution of the MTHFR 677-TT genotype. 
At a molecular level, the C677T polymorphism in the MTHFR gene is known to cause a substitution of the amino acid alanine to valine in the protein, producing a thermolabile enzyme with a reduced activity [182]. Elevated homocysteine concentrations occur in individuals with the MTHFR 677-TT genotype and is the widely recognised phenotype [182]. Hyperhomocysteinaemia has in turn been causatively associated with an increased risk of CVD although its role remains somewhat controversial [154]. Molecular evidence shows that the increased propensity for the variant form of MTHFR to dissociate from its FAD co-factor is responsible for the reduced enzyme activity of the variant enzyme in the TT genotype [183]. Interestingly, human intervention trials have reported a marked decrease in homocysteine concentrations in response to riboflavin supplementation, specifically in individuals with the TT genotype, suggesting that riboflavin can restore reduced MTHFR enzyme activity in vivo [184].

As previously mentioned, evidence from GWAS and clinical studies points to a role for one-carbon metabolism in BP and raises the possibility that intervention with relevant B vitamins may have a role in modulating BP. In this regard, a highly novel role for riboflavin in BP has emerged over the last decade from studies conducted at this Centre. The first of these was a 16-week RCT with riboflavin $(1.6 \mathrm{mg} /$ day $)$ in premature CVD patients which showed that specifically in those with the MTHFR 677-TT genotype, systolic $(-13.4 \mathrm{mmHg})$ and diastolic $(-7.5 \mathrm{mmHg}) \mathrm{BP}$ was highly responsive to riboflavin [185]. At a 4-year follow-up study, these highrisk patients with the TT genotype remained hypertensive despite the fact that antihypertensive polytherapy had been introduced in the intervening period; BP control was achieved again only in response to riboflavin [186]. In a third trial, it was shown that the genotype-specific lowering of BP in response to riboflavin was not confined to high-risk CVD patients, but was also demonstrated in hypertensive individuals without overt CVD [187]. In summary, these randomised trials show that targeted riboflavin supplementation in genetically at-risk hypertensive adults with or without CVD can effectively lower systolic BP by between 6 and $13 \mathrm{mmHg}$, irrespective of antihypertensive medication. The magnitude of such BP reductions could have an important clinical impact, given that a reduction in systolic BP of $10 \mathrm{mmHg}$ is estimated to decrease stroke risk by $40 \%$ [5]. However, the effect of riboflavin supplementation on BP in individuals with the TT genotype has not yet been investigated in other populations outside of Northern Ireland or in pregnancy.

In addition to the genotype-specific BP benefits observed in response to riboflavin, evidence for an effect of B vitamins on BP in the general population is far weaker (Table 1). In the Vitamin Intervention for Stroke Prevention (VISP) trial, 3,649 adults with nondisabling cerebral infarction were randomised to a multivitamin containing either a low dose or a high dose of B vitamins (pyridoxine, cobalamin and folic acid) for 2 years, with results showing no BP response to B vitamin intervention [188]. Similar findings were also reported by McMahon et al. [189], who investigated the effect of combined folic acid, vitamin B6 and B12 on BP in older adults and also showed no BP response. In contrast, another 2-year RCT with folic acid (5 mg/day) and pyridoxine (250 mg/day) found significant reductions in both systolic (of $3.7 \mathrm{mmHg}$ ) and diastolic (of $1.9 \mathrm{mmHg}$ ) BP in response to intervention [190].

\subsection{Biological mechanisms linking one-carbon metabolism with blood pressure}

The precise mechanisms linking one-carbon metabolism with BP, or explaining the novel role of riboflavin in BP in individuals with the TT genotype, are currently unknown. MTHFR enzyme activity is compromised in individuals with the homozygous variant MTHFR 677-TT genotype, but appears to be particularly sensitive to changes in riboflavin status [184,191]. It could therefore be speculated that in individuals with this genotype, there is a higher capacity to replace the inactivated enzyme with optimal riboflavin than with low riboflavin status, or that higher riboflavin status prevents the dissociation of the MTHFR co-factor, FAD, from the active 
site or allows its quick replacement, and in turn stabilises the variant MTHFR enzyme [192]. In this way, individuals with the TT genotype may have increased riboflavin requirements in order to sustain normal MTHFR activity. Restoration of cellular concentrations of 5-MTHF by riboflavin supplementation in those with the variant TT genotype may also correct any perturbations in one-carbon metabolism owing to this genetic variant, but this remains to be demonstrated [193].

As reviewed elsewhere, the effect of MTHFR on BP is likely to be mediated by nitric oxide, a potent vasodilator which regulates endothelial function [192]. It has been shown that patients with the TT genotype have lower vascular tissue concentrations of 5-MTHF, which in turn are linked with nitric oxide bioavailability and endothelial function [194,195]. Given that riboflavin supplementation appears to restore MTHFR activity in these genetically at-risk individuals [184], it could be speculated that 5-MTHF concentrations in the vascular tissue would increase in response to riboflavin supplementation, leading to the stimulation of eNOS and an increase in nitric oxide bioavailability, thus vasodilation and BP-lowering. Furthermore, apart from reducing 5MTHF concentrations, impaired one-carbon metabolism could also compromise the activity of dihydrofolate reductase and dihydrobiopterin reductase, impairing the conversion of dihydrobiopterin to tetrahydrobiopterin [ 196]. Whereas an increase in the bioavailability of tetrahydrobiopterin stimulates eNOS to produce nitric oxide to ultimately induce vasodilation, an accumulation of dihydrobiopterin leads to the generation of superoxide by eNOS [197,198]. Of note, given that riboflavin supplementation has been shown to elicit a BP-lowering response that is specific to individuals with the variant TT genotype in MTHFR, a direct effect at the flavoprotein binding domain of eNOS is unlikely to be the major mechanism explaining the BP-lowering role of riboflavin shown in the aforementioned intervention trials, as such an effect would likely impact BP generally and not in the observed MTHFR genotype-specific manner [199]. Furthermore, although some observational studies have suggested a role for homocysteine in BP, randomised trials primarily designed to lower homocysteine as a means to reduce CVD showed no corresponding BP response [188,189]. Therefore, homocysteine is unlikely to be directly involved in explaining the relationship of one-carbon metabolism with BP. Further research in this area is clearly required in order to fully explore these and other biological mechanisms linking one-carbon metabolism with BP and hypertension.

\section{Conclusions and future work}

Hypertension is a public health challenge of global proportions. Currently, antihypertensive treatment for the achievement of BP control is ineffective for over $40 \%$ of individuals suffering from hypertension. This emphasises the need for identification of alternative prevention and treatment strategies for hypertension. Nutrition is inextricably linked to BP and is involved in the pathogenesis and treatment of hypertension across the lifecycle. At this time, the evidence for a protective effect against hypertension is strongest in relation to the DASH diet, reduced sodium intake and increased potassium intake. Of interest, emerging evidence implicates one-carbon metabolism and related B vitamins in BP. Most notably, supplemental riboflavin may offer an effective personalised approach for managing BP in genetically at-risk individuals, albeit all the evidence in this area to date comes from trials conducted in Northern Ireland. Hence, further research is warranted to replicate such studies in different populations and in cohorts with and without existing hypertension. Mechanistic studies which will add to our understanding of the role of this gene-nutrient interaction in BP are also needed. Given that BP is known to track from early life, and hypertension in pregnancy is a major risk factor both for adverse pregnancy outcomes and later life cardiovascular events, the effect of supplementation with B vitamins on BP in pregnant women genetically at-risk of hypertension should be investigated. If a beneficial effect of relevant B vitamins on BP during pregnancy is demonstrated, a public health strategy to improve B vitamin status during 
the periconceptional and antenatal period may alleviate the health and economic burden of hypertension in pregnancy.

\section{Author contributions}

E.P. drafted the original manuscript; H.McN., K.P., M.W. and E.P. critically revised the manuscript for important intellectual content. All the authors have read and approved the final manuscript.

\section{Funding}

The first author of this paper (E.P.) received a Vice Chancellor's Research Scholarship from Ulster University for her doctoral studies. Although no direct funding was provided for this review paper, some of the research described within the article was supported by grants from the Northern Ireland HSC Public Health Agency, Research \& Development Division (Enabling Research Award) and DSM Nutritional Products (Kaiseraugst, Switzerland). The funders had no role in the decision to publish or the manuscript preparation.

\section{References}

(i) The corrections made in this section will be reviewed and approved by a journal production editor. The newly added/removed references and its citations will be reordered and rearranged by the production team.

[1] Lim S.S., Vos T., Flaxman A.D., Danaei G., Shibuya K., et al., A comparative risk assessment of burden of disease and injury attributable to 67 risk factors and risk factor clusters in 21 regions, 1990-2010: a systematic analysis for the Global Burden of Disease Study 2010, Lancet 380 (2012) 2224-2260, doi:10.1016/S0140-6736(12)61766-8.

[2] Forouzanfar M.H., Alexander L., Bachman V.F., Biryukov S., Brauer M., et al., Global, regional, and national comparative risk assessment of 79 behavioural, environmental and occupational, and metabolic risks or clusters of risks in 188 countries, 1990-2013: a systematic analysis for the Global Burden of Disease Study 2013, Lancet 386 (2015) 2287-2323, doi:10.1016/S01406736(15)00128-2.

[3] National Institute for Health and Care Excellence. Hypertension in adults: diagnosis and management management (NG136). www.nice.org.uk/guidance/ng136, 2019.

[4] National Institute for Health and Care Excellence. Hypertension in pregnancy: diagnosis and management and management (NG133). www.nice.org.uk/guidance/ng $\underline{133}, 2019$.

[5] Lewington S., Clarke R., Qizilbash N., Peto R., Collins R., et al., Age-specific relevance of blood pressure to cause-specific mortality is best assessed by collaborative meta-analysis of individual participant data from the separate prospective studies, Lancet 360 (2002) 1903-1913, doi:10.1016/S0140-6736(02)11911-8.

[6] World Health Organization. A global brief on hypertension, WHO/DCO/WHD/2013.2. (2013). $\underline{\text { htt }}$ ps://apps.who.int/iris/bitstream/handle/10665/79059/WHO_DCO_WHD_2013.2 eng.pdf; ssessioni

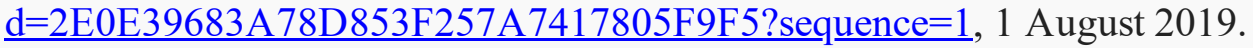


[7] Kearney P.M., Whelton M., Reynolds K., Muntner P., Whelton P.K., et al., Global burden of hypertension-analysis of worldwide data, Lancet 365 (2005) 217-223, doi:10.1016/S01406736(05)17741-1.

[8] Waterstone M., Bewley S., Wolfe C., Incidence and predictors of severe obstetric morbidity: casecontrol study, BMJ 322 (2001) 1089-1093, doi:10.1136/bmj.322.7294.1089.

[9] Slattery M.M., Geary M., Morrison J.J., Obstetric antecedents for preterm delivery, J. Perinat. Med. 36 (2008) 306-309, doi:10.1515/JPM.2008.045.

[10] Goldenberg R.L., Culhane J.F., Iams J.D., Romero R., Epidemiology and causes of preterm birth, Lancet 371 (2008) 75-84, doi:10.1016/S0140-6736(08)60074-4.

[11] Benjamin E.J., Virani S.S., Callaway C.W., Chamberlain A.M., Chang A.R., et al., Heart Disease and Stroke Statistics - 2018 Update: A Report from the American Heart Association, Lippincott Williams and Wilkins, 2018, doi:10.1161/CIR.0000000000000558.

[12] Fox A., McHugh S., Browne J., Kenny L.C., Fitzgerald A., et al., Estimating the cost of preeclampsia in the healthcare system: cross-sectional study using data from SCOPE study (Screening for pregnancy end points), Hypertension 70 (2017) 1243-1249, doi:10.1161/HYPERTENSIONAHA.117.09499.

[13] Stevens W., Shih T., Incerti D., Ton T.G.N., Lee H.C., et al., Short-term costs of preeclampsia to the United States health care system, Am, J. Obstet. Gynecol. 217 (2017) 237-248 e16, doi:10.1016/j.ajog.2017.04.032.

[14] Zhang Y., Moran A.E., Trends in the prevalence, awareness, treatment, and control of hypertension among young adults in the United States, 1999 to 2014, Hypertension 70 (2017) 736-742, doi:10.1161/HYPERTENSIONAHA.117.09801.

[15] Zhou B., Danaei G., Stevens G.A., Bixby H., Taddei C., et al., Long-term and recent trends in hypertension awareness, treatment, and control in 12 high-income countries: an analysis of 123 nationally representative surveys, Lancet 394 (2019) 639-651, doi:10.1016/s0140-6736(19)311456.

[16] Hendriks M.E., Wit F.W.N.M., Roos M.T.L., Brewster L.M., Akande T.M., et al., Hypertension in Sub-Saharan Africa: cross-sectional surveys in four rural and urban communities, PLoS One 7 (2012), doi:10.1371/journal.pone.0032638 e32638.

[17] Wilkinson J., Cole G., Preeclampsia knowledge among women in Utah, Hypertens. Pregnancy 37 (2018) 18-24, doi:10.1080/10641955.2017.1397691.

[18] Ayele G., Lemma S., Agedew E., Factors associated with hypertension during pregnancy in Derashie Woreda south Ethiopia, case control community and maternal health project officer in save the children in segen people area zone, southern nation, Qual. Prim. Care 24 (2016) 207-213.

[19] Nouko A., Awareness, treatment, and blood pressure control of hypertensive disorders in pregnancy: a multicentre study in Douala, J. Hypertens. 36 (2018) e117, doi:10.1097/01.hjh.0000548468.41300.5c. 
[20] Foëx P., Sear J.W., Hypertension: pathophysiology and treatment, Contin. Educ. Anaesthesia Crit. Care Pain 4 (2004) 71-75, doi:10.1093/bjaceaccp/mkh020.

[21] Touyz R.M., Blood pressure regulation and pathology, Cell. Mol. Pathobiol. Cardiovasc. Dis., Elsevier Inc., 2014, pp. 257-275, doi:10.1016/B978-0-12-405206-2.00014-4.

[22] J.S. Shahoud, N.R. Aeddula. Physiology, arterial pressure regulation, StatPearls publ. (2019). http s://www.ncbi.nlm.nih.gov/books/NBK538509/, 27 October 2019.

[23] Muntner P., Shimbo D., Carey R.M., Charleston J.B., Gaillard T., et al., Measurement of blood pressure in humans: a scientific statement from the American heart association, Hypertension 73 (2019) e35-e66, doi:10.1161/HYP.0000000000000087.

[24] Dionne J.M., Abitbol C.L., Flynn J.T., Hypertension in infancy: diagnosis, management and outcome, Pediatr. Nephrol. 27 (2012) 17-32, doi:10.1007/s00467-010-1755-z.

[25] National High Blood Pressure Education Program Working Group on High Blood Pressure in Children and Adolescents, The fourth report on the diagnosis, evaluation, and treatment of high blood pressure in children and adolescents, Pediatrics 114 (2004) 555-576, https://www.nhlbi.nih. gov/files/docs/resources/heart/hbp_ped.pdf.

[26] Laurent S., Antihypertensive drugs, Pharmacol. Res. $124 \quad$ (2017) 116-125, doi:10.1016/j.phrs.2017.07.026.

[27] O’Dea R.F., Mirkin B.L., Alward C.T., Sinaiko A.R., Treatment of neonatal hypertension with captopril, J. Pediatr. 113 (1988) 403-406, doi:10.1016/s0022-3476(88)80292-0.

[28] Kanbay M., Yildirir A., Bozbas H., Ulus T., Bilgi M., et al., Statin therapy helps to control blood pressure levels in hypertensive Dyslipidemic patients, Ren. Fail. 27 (2005) 297-303, doi:10.1081/JDI-56610.

[29] Presta V., Figliuzzi I., Citoni B., Miceli F., Battistoni A., et al., Effects of different statin types and dosages on systolic/diastolic blood pressure: retrospective analysis of 24-hour ambulatory blood pressure database, J. Clin. Hypertens. 20 (2018) 967-975, doi:10.1111/jch.13283.

[30] Siebenhofer A., Jeitler K., Horvath K., Berghold A., Posch N., et al., Long-term effects of weightreducing drugs in people with hypertension, Cochrane Database Syst. Rev. (2016) CD007654, doi:10.1002/14651858.CD007654.pub4.

[31] Grassi G., Quarti-Trevano F., Seravalle G., Arenare F., Brambilla G., et al., Blood pressure lowering effects of rimonabant in obesity-related hypertension, J. Neuroendocrinol. 20 (2008) 6368, doi:10.1111/j.1365-2826.2008.01688.x.

[32] Tonstad S., Tykarski A., Weissgarten J., Ivleva A., Levy B., et al., Efficacy and safety of topiramate in the treatment of obese subjects with essential hypertension, Am. J. Cardiol. 96 (2005) 243-251, doi:10.1016/j.amjcard.2005.03.053.

[33] Schiavon C.A., Bersch-Ferreira A.C., Santucci E.V., Oliveira J.D., Torreglosa C.R., et al., Effects of bariatric surgery in obese patients with hypertension the GATEWAY randomized trial (gastric 
bypass to treat obese patients with steady hypertension), Circulation 137 (2018) 1132-1142, doi:10.1161/CIRCULATIONAHA.117.032130.

[34] Schiavon C.A., Ikeoka D., V Santucci E., Santos R.N., Damiani L.P., et al., Effects of bariatric surgery versus medical therapy on the 24-hour ambulatory blood pressure and the prevalence of resistant hypertension: the GATEWAY randomized clinical trial, Hypertension 73 (2019) 571-577, doi:10.1161/HYPERTENSIONAHA.118.12290.

[35] Landsberg L., Aronne L.J., Beilin L.J., Burke V., Igel L.I., et al., Obesity-related hypertension: pathogenesis, cardiovascular risk, and treatment: a position paper of the obesity society and the American society of hypertension, J. Clin. Hypertens. 15 (2013) 14-33, doi:10.1111/jch.12049.

[36] Salihu H.M., De La Cruz C., Rahman S., August E.M., Does maternal obesity cause preeclampsia? A systematic review of the evidence, Minerva Ginecol. 64 (2012) 259-280.

[37] Mamun A.A., Lawlor D.A., O'Callaghan M.J., Williams G.M., Najman J.M., Effect of body mass index changes between ages 5 and 14 on blood pressure at age 14, Hypertension 45 (2005) 10831087, doi:10.1161/01.hyp.0000166720.18319.51.

[38] Carpio-Rivera E., Moncada-Jiménez J., Salazar-Rojas W., Solera-Herrera A., Acute effects of exercise on blood pressure: a meta-analytic investigation, Arq. Bras. Cardiol. 106 (2016) 422-433, doi:10.5935/abc.20160064.

[39] Borjesson M., Onerup A., Lundqvist S., Dahlof B., Physical activity and exercise lower blood pressure in individuals with hypertension: narrative review of 27 RCTs, Br. J. Sports Med. 50 (2016) 356-361, doi:10.1136/bjsports-2015-095786.

[40] Green M.S., Jucha E., Luz Y., Blood pressure in smokers and nonsmokers: epidemiologic findings, Am. Heart J. 111 (1986) 932-940, doi:10.1016/0002-8703(86)90645-9.

[41] Bowman T.S., Gaziano J.M., Buring J.E., Sesso H.D., A prospective study of cigarette smoking and risk of incident hypertension in women, J. Am. Coll. Cardiol. 50 (2007) 2085-2092, doi:10.1016/j.jacc.2007.08.017.

[42] Cabral M., Fonseca M.J., González-Beiras C., Santos A.C., Correia-Costa L., et al., Maternal smoking: a life course blood pressure determinant?, Nicotine Tob. Res. 20 (2018) 674-680, doi:10.1093/ntr/ntx117.

[43] Roerecke M., Kaczorowski J., Tobe S.W., Gmel G., Hasan O.S.M., et al., The effect of a reduction in alcohol consumption on blood pressure: a systematic review and meta-analysis, Lancet Publ. Health 2 (2017) e108-e120, doi:10.1016/S2468-2667(17)30003-8.

[44] Mesas A.E., Leon-Muñoz L.M., Rodriguez-Artalejo F., Lopez-Garcia E., The effect of coffee on blood pressure and cardiovascular disease in hypertensive individuals: a systematic review and meta-analysis, Am. J. Clin. Nutr. 94 (2011) 1113-1126, doi:10.3945/ajcn.111.016667.

[45] Hartley T.R., Sung B.H., Pincomb G.A., Whitsett T.L., Wilson M.F., et al., Hypertension risk status and effect of caffeine on blood pressure, Hypertension 36 (2000) 137-141, doi:10.1161/01.HYP.36.1.137. 
[46] Uiterwaal C.S., Verschuren W.M., Bueno-de-Mesquita H.B., Ocké M., Geleijnse J.M., et al., Coffee intake and incidence of hypertension, Am. J. Clin. Nutr. 85 (2007) 718-723, doi:10.1093/ajen/85.3.718.

[47] Winkelmayer W.C., Stampfer M.J., Willett W.C., Curhan G.C., Habitual caffeine intake and the risk of hypertension in women, J. Am. Med. Assoc. 294 (2005) 2330-2335, doi:10.1001/jama.294.18.2330.

[48] Ammon H.P., Biochemical mechanism of caffeine tolerance, Arch. Pharm. (Weinheim) 324 (1991) 261-267, doi:10.1002/ardp.19913240502.

[49] Wu S., Jin C., Li S., Zheng X., Zhang X., et al., Aging, arterial stiffness, and blood pressure association in Chinese adults, Hypertension $73 \quad$ (2019) 893-899, doi:10.1161/HYPERTENSIONAHA.118.12396.

[50] Franklin S.S., Ageing and hypertension: the assessment of blood pressure indices in predicting coronary heart disease, J. Hypertens. Suppl. 17 (1999) S29-S36, http://www.ncbi.nlm.nih.gov/pub

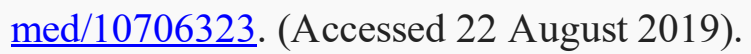

[51] Chobanian A., Bakris G., Black H., Cushman W., Green L., et al., The seventh report of the joint national committee on prevention, detection, evaluation, and treatment of high blood pressure: the JNC 7 report.,, J. Am. Med. Assoc. 289 (2003) 2560-2572.

[52] Franklin S.S., Jacobs M.J., Wong N.D., L'Italien G.J., Lapuerta P., Predominance of isolated systolic hypertension among middle-aged and elderly US hypertensives: analysis based on National Health and Nutrition Examination Survey (NHANES) III, Hypertension 37 (2001) 869874, doi:10.1161/01.HYP.37.3.869.

[53] National Center for Health Statistics. Health, United States. With special feature on mortality. Hyattsville, MD. 2018. Table 54 Hypertension among adults aged 20 and over, by selected characteristics: United States, selected years 1988-1994 through 2013-2016, (2017). https://www. cdc.gov/nchs/hus/contents2017.htm\#054, 25 August 2019.

[54] Di Giosia P., Giorgini P., Stamerra C.A., Petrarca M., Ferri C., et al., Gender differences in epidemiology, pathophysiology, and treatment of hypertension, Curr. Atherosclerosis Rep. 20 (2018) 13, doi:10.1007/s11883-018-0716-z.

[55] Ichikawa A., Sumino H., Ogawa T., Ichikawa S., Nitta K., Effects of long-term transdermal hormone replacement therapy on the renin-angiotensin-aldosterone system, plasma bradykinin levels and blood pressure in normotensive postmenopausal women, Geriatr. Gerontol. Int. 8 (2008) 259-264, doi:10.1111/j.1447-0594.2008.00474.x.

[56] Chiu C.L., Lujic S., Thornton C., O’Loughlin A., Makris A., et al., Menopausal hormone therapy is associated with having high blood pressure in postmenopausal women: observational cohort study, PLoS One 7 (2012), doi:10.1371/journal.pone.0040260 e40260.

[57] Issa Z., Seely E.W., Rahme M., Fuleihan G.E.H., Effects of hormone therapy on blood pressure, Menopause 22 (2015) 456-468, doi:10.1097/gme.0000000000000322. 
[58] Shen W., Zhang T., Li S., Zhang H., Xi B., et al., Race and sex differences of long-term blood pressure profiles from childhood and adult hypertension: the Bogalusa heart study, Hypertension 70 (2017) 66-74, doi:10.1161/HYPERTENSIONAHA.117.09537.

[59] Hottenga J.J., Boomsma D.I., Kupper N., Posthuma D., Snieder H., et al., Heritability and stability of resting blood pressure, Twin Res, Hum. Genet. 8 (2005) 499-508, doi:10.1375/183242705774310123.

[60] Miall W.E., Oldham P.D., The hereditary factor in arterial blood-pressure, BMJ 1 (1963) 75-80, doi:10.1136/bmj.1.5323.75.

[61] Ranasinghe P., Cooray D.N., Jayawardena R., Katulanda P., The influence of family history of Hypertension on disease prevalence and associated metabolic risk factors among Sri Lankan adults Chronic Disease epidemiology, BMC Publ. Health 15 (2015) 576, doi:10.1186/s12889-015-19277.

[62] Liu M., He Y., Jiang B., Wang J., Wu L., et al., Association between family history and hypertension among Chinese elderly, Medicine (Baltim.) 94 (2015) e2226, doi:10.1097/MD.0000000000002226.

[63] Ness R.B., Markovic N., Bass D., Harger G., Roberts J.M., Family history of hypertension, heart disease, and stroke among women who develop hypertension in pregnancy, Obstet. Gynecol. 102 (2003) 1366-1371, doi:10.1016/j.obstetgynecol.2003.08.011.

[64] Grindheim G., Estensen M.E., Langesaeter E., Rosseland L.A., Toska K., Changes in blood pressure during healthy pregnancy: a longitudinal cohort study, J. Hypertens. 30 (2012) 342-350, doi:10.1097/HJH.0b013e32834f0b1c.

[65] Hermida R.C., Ayala D.E., Iglesias M., Predictable blood pressure variability in healthy and complicated pregnancies, Hypertension 38 (2001) 736-741, doi:10.1161/01.HYP.38.3.736.

[66] Rebelo F., Farias D.R., Mendes R.H., Schlüssel M.M., Kac G., Blood pressure variation throughout pregnancy according to early gestational BMI: a Brazilian cohort, Arq. Bras, Cardiol. 104 (2015) 284-291, doi:10.5935/abc.20150007.

[67] James P.R., Nelson-Piercy C., Management of hypertension before, during, and after pregnancy, Heart 90 (2004) 1499-1504, doi:10.1136/hrt.2004.035444.

[68] de Haas S., Spaanderman M., Mulder E., Schartmann N., Mohseni Z., et al., 232. Adaptation of blood pressure during normotensive pregnancies and pregnancies complicated by hypertension - a systematic review and meta-analysis, Pregnancy Hypertens. 13 (2018) S106, doi:10.1016/j.preghy.2018.08.314.

[69] Garovic V.D., Bailey K.R., Boerwinkle E., Hunt S.C., Weder A.B., et al., Hypertension in pregnancy as a risk factor for cardiovascular disease later in life, J. Hypertens. 28 (2010) 826-833, doi:10.1097/HJH.0b013e328335c29a.

[70] Seely E.W., Ecker J., Chronic hypertension in pregnancy, Circulation 129 (2014) 1254-1261, doi:10.1161/CIRCULATIONAHA.113.003904. 
[71] Breathett K., Muhlestein D., Foraker R., Gulati M., Differences in preeclampsia rates between African American and Caucasian women: trends from the national hospital Discharge Survey., J. Wom. Health 23 (2014) 886-893, doi:10.1089/jwh.2014.4749.

[72] Vest A., Cho L., Hypertension in pregnancy, Cardiol. Clin. 30 (2012) 407-423.

[73] Heida K.Y., Franx A., Van Rijn B.B., Eijkemans M.J.C., Boer J.M.A., et al., Earlier age of onset of chronic hypertension and type 2 diabetes Mellitus after a hypertensive disorder of pregnancy or gestational diabetes Mellitus, Hypertension $66 \quad$ (2015) 1116-1122, doi:10.1161/HYPERTENSIONAHA.115.06005.

[74] Task Force on Blood Pressure Control in Children. Report of the second task force on blood pressure control in children -1987. National heart, Lung, and blood Institute, Bethesda, Maryland $\underline{h}$ ttp://www.ncbi.nlm.nih.gov/pubmed/3797155, 1987, 1 September 2019.

[75] Zubrow A.B., Hulman S., Kushner H., Falkner B., Determinants of blood pressure in infants admitted to neonatal intensive care units: a prospective multicenter study. Philadelphia Neonatal Blood Pressure Study Group., J. Perinatol. 15 (1995) 470-479, http://www.ncbi.nlm.nih.gov/pub med/8648456. (Accessed 21 September 2019).

[76] Samanta M., Mondal R., Ray S., Sabui T.K., Kundu C.K., et al., Blood pressure variation with gestational age and birth weight in indian newborn, J. Trop. Pediatr. 61 (2015) 197-205, doi:10.1093/tropej/fmv019.

[77] Pichler G., Cheung P.Y., Binder C., O’Reilly M., Schwaberger B., et al., Time course study of blood pressure in term and preterm infants immediately after birth, PLoS One 9 (2014), doi:10.1371/journal.pone.0114504 e114504.

[78] Batton B., Li L., Newman N.S., Das A., Watterberg K.L., et al., Evolving blood pressure dynamics for extremely preterm infants, J. Perinatol. 34 (2014) 301-305, doi:10.1038/jp.2014.6.

[79] Pejovic B., Peco-Antic A., Marinkovic-Eric J., Blood pressure in non-critically ill preterm and fullterm neonates, Pediatr. Nephrol. 22 (2007) 249-257, doi:10.1007/s00467-006-0311-3.

[80] Tan K.L., Blood pressure in full-term healthy neonates, Clin. Pediatr. (Phila) 26 (1987) 21-24, doi:10.1177/000992288702600103.

[81] Vesoulis Z.A., El Ters N.M., Wallendorf M., Mathur A.M., Empirical estimation of the normative blood pressure in infants $<28$ weeks gestation using a massive data approach, J. Perinatol. 36 (2016) 291-295, doi:10.1038/jp.2015.185.

[82] Kent A.L., Meskell S., Falk M.C., Shadbolt B., Normative blood pressure data in non-ventilated premature neonates from 28-36 weeks gestation, Pediatr. Nephrol. 24 (2009) 141-146, doi:10.1007/s00467-008-0916-9.

[83] Ingelfinger J., Hypertension in the first year of life, in: Ingelfinger J. (Ed.), Pediatr. Hypertens., WB Saunders, Philadelphia, 1982, pp. 229-240.

[84] V Jackson L., Thalange N.K.S., Cole T.J., Blood pressure centiles for Great Britain, Arch. Dis. Child. 92 (2007) 298-303, doi:10.1136/adc.2005.081216. 
[85] Theodore R.F., Broadbent J., Nagin D., Ambler A., Hogan S., et al., Childhood to early-midlife systolic blood pressure trajectories: early-life predictors, effect modifiers, and adult cardiovascular outcomes., Hypertension 66 (2015) 1108-1115, doi:10.1161/HYPERTENSIONAHA.115.05831.

[86] Hao G., Wang X., Treiber F.A., Harshfield G., Kapuku G., et al., Blood pressure trajectories from childhood to young adulthood associated with cardiovascular risk: results from the 23-year longitudinal Georgia stress and heart study, Hypertension 69 (2017) 435-442, doi:10.1161/HYPERTENSIONAHA.116.08312.

[87] Bao W., Threefoot S.A., Srinivasan S.R., Berenson G.S., Essential hypertension predicted by tracking of elevated blood pressure from childhood to adulthood: the Bogalusa Heart Study, Am. J. Hypertens. 8 (1995) 657-665, doi:10.1016/0895-7061(95)00116-7.

[88] Drukteinis J.S., Roman M.J., Fabsitz R.R., Lee E.T., Best L.G., et al., Cardiac and systemic hemodynamic characteristics of hypertension and prehypertension in adolescents and young adults: the Strong Heart Study, Circulation $115 \quad$ (2007) 221-227, doi:10.1161/CIRCULATIONAHA.106.668921.

[89] Lande M.B., Carson N.L., Roy J., Meagher C.C., Effects of childhood primary hypertension on carotid intima media thickness: a matched controlled study, Hypertension 48 (2006) 40-44, doi:10.1161/01.HYP.0000227029.10536.e8.

[90] Hansen M.L., Gunn P.W., Kaelber D.C., Underdiagnosis of hypertension in children and adolescents, J. Am. Med. Assoc. 298 (2007) 874-879, doi:10.1001/jama.298.8.874.

[91] Vasan R.S., Beiser A., Seshadri S., Larson M.G., Kannel W.B., et al., Residual lifetime risk for developing hypertension in middle-aged women and men: the Framingham Heart Study.,, J. Am. Med. Assoc. 287 (2002) 1003-1010, doi:10.1001/jama.287.8.1003.

[92] Allen N., Berry J.D., Ning H., Van Horn L., Dyer A., et al., Impact of blood pressure and blood pressure change during middle age on the remaining lifetime risk for cardiovascular disease: the cardiovascular lifetime risk pooling project, Circulation $125 \quad$ (2012) 37-44, doi:10.1161/CIRCULATIONAHA.110.002774.

[93] Park H., Kim K., Associations between oral contraceptive use and risks of hypertension and prehypertension in a cross-sectional study of Korean women, BMC Womens, Health 13 (2013), doi:10.1186/1472-6874-13-39.

[94] Chiu C.L., Lind J.M., Past oral contraceptive use and self-reported high blood pressure in postmenopausal women, BMC Publ. Health 15 (2015), doi:10.1186/s12889-015-1392-3.

[95] Zhang Y., Vittinghoff E., Pletcher M.J., Allen N.B., Zeki Al Hazzouri A., et al., Associations of blood pressure and cholesterol levels during young adulthood with later cardiovascular events, J. Am. Coll. Cardiol. 74 (2019) 330-341, doi:10.1016/j.jacc.2019.03.529.

[96] Vasconcellos H.D., Moreira H.T., Ciuffo L., Nwabuo C.C., Yared G.S., et al., Cumulative blood pressure from early adulthood to middle age is associated with left atrial remodelling and subclinical dysfunction assessed by three-dimensional echocardiography: a prospective post hoc 
analysis from the coronary Artery Risk Development i, Eur. Heart J. Cardiovasc. Imag. 19 (2018) 977-984, doi:10.1093/ehjci/jey086.

[97] Lane C.A., Barnes J., Nicholas J.M., Sudre C.H., Cash D.M., et al., Associations between blood pressure across adulthood and late-life brain structure and pathology in the neuroscience substudy of the 1946 British birth cohort (Insight 46): an epidemiological study, Lancet Neurol. 18 (2019) 942-952, doi:10.1016/S1474-4422(19)30228-5.

[98] Joffres M., Falaschetti E., Gillespie C., Robitaille C., Loustalot F., et al., Hypertension prevalence, awareness, treatment and control in national surveys from England, the USA and Canada, and correlation with stroke and ischaemic heart disease mortality: a cross-sectional study, BMJ Open 3 (2013), doi:10.1136/bmjopen-2013-003423 e003423.

[99] Delgado J., Bowman K., Ble A., Masoli J., Han Y., et al., Blood pressure trajectories in the 20 years before death, JAMA Intern. Med. $178 \quad$ (2018) 93-99, doi:10.1001/jamainternmed.2017.7023.

[100] Ravindrarajah R., Hazra N.C., Hamada S., Charlton J., Jackson S.H.D., et al., Systolic blood pressure trajectory, frailty, and all-cause mortality $>80$ Years of age: cohort study using electronic $\begin{array}{lllll}\text { health } & \text { records, } & \text { Circulation } & \text { 2357-2368, }\end{array}$ doi:10.1161/CIRCULATIONAHA.116.026687.

[101] Zhou D., Xi B., Zhao M., Wang L., Veeranki S.P., Uncontrolled hypertension increases risk of allcause and cardiovascular disease mortality in US adults: the NHANES III Linked Mortality Study, Sci. Rep. 8 (2018) 9418, doi:10.1038/s41598-018-27377-2.

[102] Bavishi C., Bangalore S., Messerli F.H., Outcomes of intensive blood pressure lowering in older hypertensive patients, J. Am. Coll. Cardiol. 69 (2017) 486-493, doi:10.1016/j.jacc.2016.10.077.

[103] SPRINT Research Group, A randomized trial of intensive versus standard blood-pressure control, N. Engl, J. Med. 373 (2015) 2103-2116.

[104] Delgado J., Masoli J.A.H., Bowman K., Strain W.D., Kuchel G.A., et al., Outcomes of treated hypertension at age 80 and older: cohort analysis of 79,376 individuals, J. Am. Geriatr. Soc. 65 (2017) 995-1003, doi:10.1111/jgs.14712.

[105] Tinetti M.E., Han L., Lee D.S.H., McAvay G.J., Peduzzi P., et al., Antihypertensive medications and serious fall injuries in a nationally representative sample of older adults, JAMA Intern. Med. 174 (2014) 588-595, doi:10.1001/jamainternmed.2013.14764.

[106] Klein D., Nagel G., Kleiner A., Ulmer H., Rehberger B., et al., Blood pressure and falls in community-dwelling people aged 60 years and older in the VHM\&PP cohort, BMC Geriatr. 13 (2013), doi:10.1186/1471-2318-13-50.

[107] Bromfield S.G., Ngameni C.A., Colantonio L.D., Barrett Bowling C., Shimbo D., et al., Blood pressure, antihypertensive polypharmacy, frailty, and risk for serious fall injuries among older treated adults with hypertension, Hypertension $70 \quad$ (2017) 259-266, doi:10.1161/HYPERTENSIONAHA.116.09390. 
[108] Streit S., Poortvliet R.K.E., Den Elzen W.P.J., Blom J.W., Gussekloo J., Systolic blood pressure and cognitive decline in older adults with hypertension, Ann. Fam. Med. 17 (2019) 100-107, doi:10.1370/afm.2367.

[109] Perng W., Rifas-Shiman S.L., Kramer M.S., Haugaard L.K., Oken E., et al., Early weight gain, linear growth, and mid-childhood blood pressure: a prospective study in project Viva, Hypertension 67 (2016) 301-308, doi:10.1161/HYPERTENSIONAHA.115.06635.

[110] Look A.H.E.A.D., Research group, reduction in weight and cardiovascular disease risk factors in individuals with type 2 diabetes: one-year results of the Look AHEAD trial, Diabetes Care 30 (2007) 1374-1383, doi:10.2337/dc07-0048.

[111] Appel L.J., Moore T.J., Obarzanek E., Vollmer W.M., Svetkey L.P., et al., A clinical trial of the effects of dietary patterns on blood pressure. DASH Collaborative Research Group, N. Engl, J. Med. 336 (1997) 1117-1124, doi:10.1056/NEJM199704173361601.

[112] Hinderliter A.L., Sherwood A., Craighead L.W., Lin P.H., Watkins L., et al., The long-term effects of lifestyle change on blood pressure: one-year follow-up of the ENCORE study, Am. J. Hypertens. 27 (2014) 734-741, doi:10.1093/ajh/hpt183.

[113] Arvizu M., Stuart J., Rich-Edwards J., Gaskins A., Rosner B., et al., Adherence to pre-pregnancy DASH dietary pattern and diet recommendations from the American heart association and the risk of preeclampsia (OR35-06-19), Curr. Dev. Nutr. 3 (2019) 956, doi:10.1093/cdn/nzz048.or35-0619.

[114] Couch S.C., Saelens B.R., Levin L., Dart K., Falciglia G., et al., The efficacy of a clinic-based behavioral nutrition intervention emphasizing a DASH-type diet for adolescents with elevated blood pressure, J. Pediatr. 152 (2008) 494-501.

[115] Saneei P., Hashemipour M., Kelishadi R., Rajaei S., Esmaillzadeh A., Effects of recommendations to follow the Dietary Approaches to Stop Hypertension (DASH) diet v. usual dietary advice on childhood metabolic syndrome: a randomised cross-over clinical trial, Br. J. Nutr. 110 (2013) 2250-2259, doi:10.1017/S0007114513001724.

[116] Aljuraiban G.S., Stamler J., Chan Q., Van Horn L., Daviglus M.L., et al., Relations between dairy product intake and blood pressure: the INTERnational study on MAcro/micronutrients and blood Pressure, J. Hypertens. 36 (2018) 2049-2058, doi:10.1097/HJH.0000000000001779.

[117] Sacks F.M., Svetkey L.P., Vollmer W.M., Appel L.J., Bray G.A., et al., Effects on blood pressure of reduced dietary sodium and the dietary approaches to Stop hypertension (DASH) diet. DASHsodium collaborative research group, N. Engl. J. Med. 344 (2001) 3-10, doi:10.1056/NEJM200101043440101.

[118] Vollmer W.M., Sacks F.M., Ard J., Appel L.J., Bray G.A., et al., DASH-Sodium Trial Collaborative Research Group, Effects of diet and sodium intake on blood pressure: subgroup analysis of the DASH-sodium trial, Ann. Intern. Med. 135 (2001) 1019-1028, doi:10.7326/00034819-135-12-200112180-00005. 
Davis C., Bryan J., Hodgson J., Murphy K., Definition of the mediterranean diet: a literature review, Nutrients 7 (2015) 9139-9153, doi:10.3390/nu7115459.

[120] Estruch R., Martínez-González M.A., Corella D., Salas-Salvadó J., Ruiz-Gutiérrez V., et al., Effects of a mediterranean-style diet on cardiovascular risk factors a randomized trial, Ann. Intern. Med. 145 (2006) 1-11, doi:10.7326/0003-4819-145-1-200607040-00004.

[121] Medina-Remón A., Estruch R., Tresserra-Rimbau A., Vallverdú-Queralt A., Lamuela-Raventos R.M., The effect of polyphenol consumption on blood pressure, Mini Rev. Med. Chem. 13 (2013) 1137-1149, doi:10.2174/1389557511313080002.

[122] La Verde M., Mulè S., Zappalà G., Privitera G., Maugeri G., et al., Higher Adherence to the Mediterranean Diet Is Inversely Associated with Having Hypertension: Is Low Salt Intake a Mediating Factor?, Int. J. Food Sci. Nutr, 69, 2018, pp. 235-244, doi:10.1080/09637486.2017.1350941.

[123] Zhao C.N., Meng X., Li Y., Li S., Liu Q., et al., Fruits for prevention and treatment of cardiovascular diseases, Nutrients 9 (2017), doi:10.3390/nu9060598.

[124] Hobbs D.A., Kaffa N., George T.W., Methven L., Lovegrove J.A., Blood pressure-lowering effects of beetroot juice and novel beetroot-enriched bread products in normotensive male subjects, Br. J. Nutr. 108 (2012) 2066-2074.

[125] Ocampo D.A.B., Paipilla A.F., Marín E., Vargas-Molina S., Petro J.L., et al., Dietary nitrate from beetroot juice for hypertension: a systematic review, Biomolecules 8 (2018) 134, doi:10.3390/biom8040134.

[126] He F.J., Li J., MacGregor G.A., Effect of longer term modest salt reduction on blood pressure: Cochrane systematic review and meta-analysis of randomised trials, BMJ 346 (2013) f1325, doi:10.1136/bmj.f1325.

[127] Intersalt Cooperative Research Group, Intersalt: an international study of electrolyte excretion and blood, Br. Med. J. 297 (1988) 319-328, doi:10.1136/bmj.297.6644.319.

[128] Nishida C., Uauy R., Kumanyika S., Shetty P., The Joint WHO/FAO Expert Consultation on diet, nutrition and the prevention of chronic diseases: process, product and policy implications,, Publ. Health Nutr. 7 (2004) 245-250, doi:10.1079/phn2003592.

[129] Cook N.R., Cohen J., Hebert P.R., Taylor J.O., Hennekens C.H., Implications of small reductions in diastolic blood pressure for primary prevention., Arch. Intern. Med. 155 (1995) 701-709, http:// www.ncbi.nlm.nih.gov/pubmed/7695458. (Accessed 6 October 2019).

[130] Huang L., Trieu K., Yoshimura S., Neal B., Woodward M., et al., Effect of dose and duration of reduction in dietary sodium on blood pressure levels: systematic review and meta-analysis of randomised trials, BMJ (2020) m315, doi:10.1136/bmj.m315.

[131] Weinberger M.H., Miller J.Z., Luft F.C., Grim C.E., Fineberg N.S., Definitions and characteristics of sodium sensitivity and blood pressure resistance, Hypertension 8 (1986) II-127-II-134, doi:10.1161/01.HYP.8.6_Pt_2.II127. 
[132] Sullivan J.M., Prewitt R.L., Ratts T.E., Sodium sensitivity in normotensive and borderline hypertensive humans, Am. J. Med. Sci. 295 (1988) 370-377, doi:10.1097/00000441-19880400000025.

[133] Luzardo L., Noboa O., Boggia J., Mechanisms of salt-sensitive hypertension, Curr. Hypertens. Rev. 11 (2015) 14-21, doi:10.2174/1573402111666150530204136.

[134] Elijovich F., Weinberger M.H., Anderson C.A.M., Appel L.J., Bursztyn M., et al., Salt sensitivity of blood pressure: a scientific statement from the American heart association, Hypertension 68 (2016) e7-e46, doi:10.1161/HYP.0000000000000047.

[135] Aburto N.J., Hanson S., Gutierrez H., Hooper L., Elliott P., et al., Effect of increased potassium intake on cardiovascular risk factors and disease: systematic review and meta-analyses, BMJ 346 (2013) f1378, doi:10.1136/bmj.f1378.

[136] Paulino-Morente J.M.A., Cacas-David I.G., Penolio V.V.L., Association of hypokalemia and preeclampsia and correlation of levels of serum potassium to blood pressure severity in preeclampsia, Philippine J. Obstet. Gynecol. 42 (2018) 9-16.

[137] McCarron D.A., Morris C.D., Blood pressure response to oral calcium in persons with mild to moderate hypertension. A randomized, double-blind, placebo-controlled, crossover trial, Ann. Intern. Med. 103 (1985) 825-831, doi:10.7326/0003-4819-103-6-825.

[138] Strazzullo P., Siani A., Guglielmi S., Carlo A.D.I., Galletti F., et al., Controlled trial of long-term oral calcium supplementation in essential hypertension, Hypertension 8 (1986) 1084-1088, http://a hajournals.org.

[139] Grobbee D.E., Hofman A., Effect of calcium supplementation on diastolic blood pressure in young people with mild hypertension, Lancet 328 (1986) 703-707, doi:10.1016/S01406736(86)90228-X.

[140] Hatton D.C., Harrison-Hohner J., Coste S., Reller M., McCarron D., Gestational calcium supplementation and blood pressure in the offspring, Am. J. Hypertens. 16 (2003) 801-805, doi:10.1016/S0895-7061(03)01027-6.

[141] Gillman M.W., Rifas-Shiman S.L., Kleinman K.P., Rich-Edwards J.W., Lipshultz S.E., Maternal calcium intake and offspring blood pressure, Circulation 110 (2004) 1990-1995, doi:10.1161/01.CIR.0000143199.93495.96.

[142] Hofmeyr G.J., Lawrie T.A., Atallah A.N., Torloni M.R., Calcium supplementation during pregnancy for preventing hypertensive disorders and related problems, Cochrane Libr. (2018) CD001059, doi:10.1002/14651858.CD001059.pub5.

[143] Zhang X., Li Y., Del Gobbo L.C., Rosanoff A., Wang J., et al., Effects of magnesium supplementation on blood pressure: a meta-analysis of randomized double-blind placebo-controlled trials, Hypertension 68 (2016) 324-333, doi:10.1161/HYPERTENSIONAHA.116.07664.

[144] Rosanoff A., Magnesium supplements may enhance the effect of antihypertensive medications in stage 1 hypertensive subjects, Magnes. Res. 23 (2010) 27-40, doi:10.1684/mrh.2010.0198. 
[145] Tresserra-Rimbau A., Rimm E.B., Medina-Remón A., Martínez-González M.A., de la Torre R., et al., Inverse association between habitual polyphenol intake and incidence of cardiovascular events in the PREDIMED study, Nutr. Metabol. Cardiovasc. Dis. 24 (2014) 639-647, doi:10.1016/j.numecd.2013.12.014.

[146] Miranda A.M., Steluti J., Fisberg R.M., Marchioni D.M., Association between polyphenol intake and hypertension in adults and older adults: a population-based study in Brazil,, PLoS One 11 (2016) e0165791, doi:10.1371/journal.pone.0165791.

[147] Moreno-Luna R., Muñoz-Hernandez R., Miranda M.L., Costa A.F., Jimenez-Jimenez L., et al., Olive oil polyphenols decrease blood pressure and improve endothelial function in young women with mild hypertension, Am. J. Hypertens. 25 (2012) 1299-1304, doi:10.1038/ajh.2012.128.

[148] Shiina K., Tomiyama H., Matsumoto C., Komatsu S., Natsume M., et al., Gender difference in the effects of cacao polyphenols on blood pressure and glucose/lipid metabolism in prediabetic subjects: a double-blinded, randomized, placebo-controlled crossover trial, Hypertens. Res. 42 (2019) 1083-1085, doi:10.1038/s41440-019-0208-8.

[149] Godos J., Vitale M., Micek A., Ray S., Martini D., et al., Dietary polyphenol intake, blood pressure, and hypertension: a systematic review and meta-analysis of observational studies,, Antioxidants 8 (2019) 152, doi:10.3390/antiox8060152.

[150] Forman J.P., Scott J.B., Ng K., Drake B.F., Suarez E., et al., Effect of vitamin d supplementation on blood pressure in blacks, Hypertension 61 (2013) 779-785, doi:10.1161/HYPERTENSIONAHA.111.00659.

[151] He S., Hao X., The effect of vitamin D3 on blood pressure in people with vitamin D deficiency: a system review and meta-analysis, Medicine (Baltim.) 98 (2019), doi:10.1097/MD.0000000000015284 e15284.

[152] Bailey L.B., Stover P.J., McNulty H., Fenech M.F., Gregory J.F., et al., Biomarkers of nutrition for development—folate review, J. Nutr. 145 (2015) 1636S-1680S, doi:10.3945/jn.114.206599.

[153] Foraker A.B., Khantwal C.M., Swaan P.W., Current perspectives on the cellular uptake and trafficking of riboflavin, Adv. Drug Deliv. Rev. 55 (2003) 1467-1483, doi:10.1016/j.addr.2003.07.005.

[154] Ducker G.S., Rabinowitz J.D., One-carbon metabolism in health and disease, Cell Metabol. 25 (2017) 27-42, doi:10.1016/j.cmet.2016.08.009.

[155] Newton-Cheh C., Johnson T., Gateva V., Tobin M.D., Bochud M., et al., Genome-wide association study identifies eight loci associated with blood pressure, Nat. Genet. 41 (2009) 666676, doi:10.1038/ng.361.

[156] McNulty H., Ward M., Hoey L., Hughes C.F., Pentieva K., Addressing optimal folate and related B-vitamin status through the lifecycle: health impacts and challenges, Proc. Nutr. Soc. 78 (2019) 449-462, doi:10.1017/S0029665119000661. 
McNulty B., McNulty H., Marshall B., Ward M., Molloy A.M., et al., Impact of continuing folic acid after the first trimester of pregnancy: findings of a randomized trial of Folic Acid Supplementation in the Second and Third Trimesters, Am, J. Clin. Nutr. 98 (2013) 92-98, doi:10.3945/ajcn.112.057489.

[158] Fletcher J., Gurr A., Fellingham F.R., Prankerd T.A.J., Brant H.A., et al., The value of folic acid supplements in pregnancy, BJOG 78 (1971) 781-785, doi:10.1111/j.1471-0528.1971.tb00338.x.

[159] Homocysteine Lowering Trialists' Collaboration, Dose-dependent effects of folic acid on blood concentrations of homocysteine: a meta-analysis of the randomized trials., Am, J. Clin. Nutr. 82 (2005) 806-812, doi:10.1093/ajcn/82.4.806.

[160] De Ocampo M.P.G., Araneta M.R.G., Macera C.A., Alcaraz J.E., Moore T.R., et al., Folic acid supplement use and the risk of gestational hypertension and preeclampsia, Women Birth J. Aust. Coll. Midwives 31 (2018) e77-e83, doi:10.1016/j.wombi.2017.08.128.

[161] Serrano N.C., Quintero-Lesmes D.C., Becerra-Bayona S., Guio E., Beltran M., et al., Association of pre-eclampsia risk with maternal levels of folate, homocysteine and vitamin B12 in Colombia: a case-control study,, PLoS One 13 (2018), doi:10.1371/journal.pone.0208137 e0208137.

[162] Cotter A.M., Molloy A.M., Scott J.M., Daly S.F., Elevated plasma homocysteine in early pregnancy: a risk factor for the development of severe preeclampsia, Am, J. Obstet. Gynecol. 185 (2001) 781-785, doi:10.1067/mob.2001.117304.

[163] Cotter A.M., Molloy A.M., Scott J.M., Daly S.F., Elevated plasma homocysteine in early pregnancy: a risk factor for the development of nonsevere preeclampsia, Am, J. Obstet. Gynecol. 189 (2003) 391-394, doi:10.1067/mob.2001.117304.

[164] Goddijn-Wessel T.A., Wouters M.G., van de Molen E.F., Spuijbroek M.D., Steegers-Theunissen R.P., et al., Hyperhomocysteinemia: a risk factor for placental abruption or infarction, Eur. J. Obstet. Gynecol. Reprod. Biol. 66 (1996) 23-29, doi:10.1016/0301-2115(96)02383-4.

[165] Nelen W.L., Blom H.J., Steegers E.A., den Heijer M., Eskes T.K., Hyperhomocysteinemia and recurrent early pregnancy loss: a meta-analysis, Fertil. Steril. 74 (2000) 1196-1199, doi:10.1016/s0015-0282(00)01595-8.

[166] Dodds L., Fell D.B., Dooley K.C., Armson B.A., Allen A.C., et al., Effect of homocysteine concentration in early pregnancy on gestational hypertensive disorders and other pregnancy outcomes, Clin. Chem. 54 (2008) 326-334, doi:10.1373/clinchem.2007.097469.

[167] Vollset S.E., Refsum H., Irgens L.M., Emblem B.M., Tverdal A., et al., Plasma total homocysteine, pregnancy complications, and adverse pregnancy outcomes: the Hordaland Homocysteine Study, Am, J. Clin. Nutr. 71 (2000) 962-968, doi:10.1097/00006254-20001000000002.

[168] Wen S.W., White R.R., Rybak N., Gaudet L.M., Robson S., et al., Effect of high dose folic acid supplementation in pregnancy on pre-eclampsia (FACT): double blind, Phase III, randomised controlled, international, multicentre trial, BMJ $362 \quad$ (2018) k3478, doi:10.1097/01.ogx.0000553100.78470.9a. 
[169] Niu W.-Q., You Y.-G., Qi Y., Strong association of methylenetetrahydrofolate reductase gene C677T polymorphism with hypertension and hypertension-in-pregnancy in Chinese: a metaanalysis, J. Hum. Hypertens. 26 (2012) 259-267, doi:10.1038/jhh.2011.11.

[170] Yang B., Fan S., Zhi X., Li Y., Liu Y., et al., Associations of MTHFR gene polymorphisms with hypertension and hypertension in pregnancy: a meta-analysis from 114 studies with 15411 cases and 21970 controls, PLoS One 9 (2014), doi:10.1371/journal.pone.0087497 e87497.

[171] Ehret G.B., Munroe P.B., Rice K.M., Bochud M., Johnson A.D., et al., Genetic variants in novel pathways influence blood pressure and cardiovascular disease risk., Nature 478 (2011) 103-109, doi:10.1038/nature10405.

[172] McNulty H., Strain J.J., Hughes C.F., Ward M., Riboflavin, MTHFR genotype and blood pressure: a personalized approach to prevention and treatment of hypertension, Mol. Aspect. Med. 53 (2017) 2-9, doi:10.1016/j.mam.2016.10.002.

[173] Huo Y., Li J., Qin X., Huang Y., Wang X., et al., Efficacy of folic acid therapy in primary prevention of stroke among adults with hypertension in China: the CSPPT randomized clinical trial,, J. Am. Med. Assoc. 313 (2015) 1325-1335, doi:10.1001/jama.2015.2274.

[174] Qian X., Lu Z., Tan M., Liu H., Lu D., A meta-analysis of association between C677T polymorphism in the methylenetetrahydrofolate reductase gene and hypertension, Eur. J. Hum. Genet. 15 (2007) 1239-1245, doi:10.1038/sj.ejhg.5201914.

[175] Wu X., Yang K., Tang X., Sa Y., Zhou R., et al., Folate metabolism gene polymorphisms MTHFR C677T and A1298C and risk for preeclampsia: a meta-analysis, J. Assist. Reprod. Genet. 32 (2015) 797-805, doi:10.1007/s10815-014-0408-8.

[176] Yang Q., Botto L.D., Erickson J.D., Berry R.J., Sambell C., et al., Improvement in stroke mortality in Canada and the United States, 1990 to 2002, Circulation 113 (2006) 1335-1343, doi:10.1161/CIRCULATIONAHA.105.570846.

[177] Yang K.M., Jia J., Mao L.-N., Men C., Tang K.-T., et al., Methylenetetrahydrofolate reductase C677T gene polymorphism and essential hypertension: a meta-analysis of 10,415 subjects, Biomed. Rep. 2 (2014) 699-708, doi:10.3892/br.2014.302.

[178] McNulty H., Strain J.J., Pentieva K., Ward M., One-carbon metabolism and CVD outcomes in older adults, Proc. Nutr. Soc. 71 (2012) 213-221, doi:10.1017/S0029665111003387.

[179] Wilcken B., Bamforth F., Li Z., Zhu H., Ritvanen A., et al., Geographical and ethnic variation of the $677 \mathrm{C}>\mathrm{T}$ allele of 5,10 methylenetetrahydrofolate reductase (MTHFR): findings from over 7000 newborns from 16 areas world wide, J. Med. Genet. 40 (2003) 619-625.

[180] Wang X., Fu J., Li Q., Zeng D., Geographical and ethnic distributions of the MTHFR C677T, A1298C and MTRR A66G gene polymorphisms in Chinese populations: A meta-analysis, PLoS One 11 (2016), doi:10.1371/journal.pone.0152414 e0152414.

[181] Contreras-Cubas C., Sánchez-Hernández B.E., García-Ortiz H., Martínez-Hernández A., BarajasOlmos F., et al., Heterogenous distribution of MTHFR gene variants among mestizos and diverse 
amerindian groups from Mexico, PLoS One $11 \quad$ (2016) e0163248, doi:10.1371/journal.pone.0163248.

[182] Frosst P., Blom H.J., Milos R., Goyette P., Sheppard C.A., et al., A candidate genetic risk factor for vascular disease: a common mutation in methylenetetrahydrofolate reductase,, Nat. Genet. 10 (1995) 111-113, doi:10.1038/ng0595-111.

[183] Yamada K., Chen Z., Rozen R., Matthews R.G., Effects of common polymorphisms on the properties of recombinant human methylenetetrahydrofolate reductase, Proc. Natl. Acad. Sci. U. S. A. 98 (2001) 14853-14858, doi:10.1073/pnas.261469998.

[184] McNulty H., Dowey L.R.C., Strain J.J., Dunne A., Ward M., et al., Riboflavin lowers homocysteine in individuals homozygous for the MTHFR $677 \mathrm{C} \rightarrow \mathrm{T}$ polymorphism, Circulation 113 (2006) 74-80, doi:10.1161/CIRCULATIONAHA.105.580332.

[185] Horigan G., McNulty H., Ward M., Strain J.J., Purvis J., et al., Riboflavin lowers blood pressure in cardiovascular disease patients homozygous for the 677C-->T polymorphism in MTHFR, J. Hypertens. 28 (2010) 478-486, doi:10.1097/HJH.0b013e328334c126.

[186] Wilson C.P., Ward M., McNulty H., Strain J.J., Trouton T.G., et al., Riboflavin offers a targeted strategy for managing hypertension in patients with the MTHFR 677TT genotype: a 4-y followup, Am, J. Clin. Nutr. 95 (2012) 766-772, doi:10.3945/ajcn.111.026245.

[187] Wilson C.P., McNulty H., Ward M., Strain J.J., Trouton T.G., et al., Blood pressure in treated hypertensive individuals with the MTHFR 677TT genotype is responsive to intervention with riboflavin: findings of a targeted randomized trial, Hypertension 61 (2013) 1302-1308, doi:10.1161/HYPERTENSIONAHA.111.01047.

[188] Toole J.F., Malinow M.R., Chambless L.E., Spence J.D., Pettigrew L.C., et al., Lowering homocysteine in patients with Ischemic stroke to prevent recurrent stroke, myocardial infarction, and death: the vitamin intervention for stroke prevention (VISP) randomized controlled trial,, J. Am. Med. Assoc. 291 (2004) 565-575, doi:10.1001/jama.291.5.565.

[189] McMahon J.A., Skeaff C.M., Williams S.M., Green T.J., Lowering homocysteine with B vitamins has no effect on blood pressure in older adults, J. Nutr. 137 (2007) 1183-1187, doi:10.1093/jn/137.5.1183.

[190] Van Dijk R.A.J.M., Rauwerda J.A., Steyn M., Twisk J.W.R., Stehouwer C.D.A., Long-term homocysteine-lowering treatment with folic acid plus pyridoxine is associated with decreased blood pressure but not with improved brachial artery endothelium-dependent vasodilation or carotid artery stiffness: a 2-year, randomized, placebo-contr, Arterioscler. Thromb. Vasc. Biol. 21 (2001) 2072-2079, doi:10.1161/hq1201.100223.

[191] Hustad S., Midttun Ø., Schneede J., Vollset S.E., Grotmol T., et al., The methylenetetrahydrofolate reductase $677 \mathrm{C} \rightarrow \mathrm{T}$ polymorphism as a modulator of a B-vitamin network with major effects on homocysteine metabolism, Am. J. Hum. Genet. 80 (2007) 846-855, doi:10.1086/513520.

[192] McNulty H., Strain J.J., Hughes C.F., Pentieva K., Ward M., Evidence of a role for one-carbon metabolism in blood pressure: can B vitamin intervention address the genetic risk of hypertension 
owing to a common folate polymorphism?, Curr. Dev. Nutr. 4 (2020) nzz102, doi:10.1093/cdn/nzz102.

[193] Bagley P.J., Selhub J., A common mutation in the methylenetetrahydrofolate reductase gene is associated with an accumulation of formylated tetrahydrofolates in red blood cells, Proc. Natl. Acad. Sci. U.S.A. 95 (1998) 13217-13220, doi:10.1073/pnas.95.22.13217.

[194] Antoniades C., Shirodaria C., Warrick N., Cai S., de Bono J., et al., 5-methyltetrahydrofolate rapidly improves endothelial function and decreases superoxide production in human vessels: effects on vascular tetrahydrobiopterin availability and endothelial nitric oxide synthase coupling, Circulation 114 (2006) 1193-1201, doi:10.1161/CIRCULATIONAHA.106.612325.

[195] Antoniades C., Shirodaria C., Leeson P., Baarholm O.A., Van-Assche T., et al., MTHFR 677 C>T Polymorphism reveals functional importance for 5-methyltetrahydrofolate, not homocysteine, in regulation of vascular redox state and endothelial function in human atherosclerosis, Circulation 119 (2009) 2507-2515, doi:10.1161/CIRCULATIONAHA.108.808675.

[196] Schmidt K., Kolesnik B., Gorren A.C., Werner E.R., Mayer B., Cell type-specific recycling of tetrahydrobiopterin by dihydrofolate reductase explains differential effects of 7,8-dihydrobiopterin on endothelial nitric oxide synthase uncoupling, Biochem. Pharmacol. 90 (2014) 246-253, doi:10.1016/j.bcp.2014.05.010.

[197] Crabtree M.J., Tatham A.L., Al-Wakeel Y., Warrick N., Hale A.B., et al., Quantitative regulation of intracellular endothelial nitric-oxide synthase (eNOS) coupling by both tetrahydrobiopterineNOS stoichiometry and biopterin redox status: insights from cells with tet-regulated GTP cyclohydrolase I expression, J. Biol. Chem. 284 (2009) 1136-1144, doi:10.1074/jbc.M805403200.

[198] Crabtree M.J., Channon K.M., Synthesis and recycling of tetrahydrobiopterin in endothelial function and vascular disease, Nitric Oxide 25 (2011) 81-88, doi:10.1016/j.niox.2011.04.004.

[199] Stuehr D.J., Tejero J., Haque M.M., Structural and mechanistic aspects of flavoproteins: electron transfer through the nitric oxide synthase flavoprotein domain, FEBS J. 276 (2009) 3959-3974, doi:10.1111/j.1742-4658.2009.07120.x.

「2001 Gu D.. He ... Wu X.. Duan X.. Whelton P.K.. Effect of notassium sunnlementation on hlood

\section{Highlights}

- Hypertension is the leading cause of mortality worldwide, typically from CVD.

- Intervention to effectively lower blood pressure (BP) can reduce CVD risk.

- Nutritional factors can influence BP and risk of hypertension across the lifecycle.

- Emerging evidence points to a novel role for one-carbon metabolism in BP.

- Riboflavin (MTHFR co-factor) lowers BP in individuals with the MTHFR 677-TT genotype. 


\section{Queries and Answers}

Query: Your article is registered as belonging to the Special Issue/Collection entitled "B vitamins and one carbon". If this is NOT correct and your article is a regular item or belongs to a different Special Issue please contact M.Renaud@elsevier.com immediately prior to returning your corrections.

Answer: Thank you for your message. We confirm that this article was correctly registered as belonging to the Special Issue entitld "B vitamins and one-carbon metabolism in health and disease".

Query: Please confirm that given names and surnames have been identified correctly and are presented in the desired order and please carefully verify the spelling of all authors' names.

Answer: We confirm that the given names and surnames of all authors are correctly spelled, identified and presented in the desired order.

Query: Please confirm that the provided email "h.mcnulty@ulster.ac.uk" is the correct address for official communication, else provide an alternate e-mail address to replace the existing one, because private e-mail addresses should not be used in articles as the address for communication.

Answer: We confirm that "h.mcnulty@ulster.ac.uk" is the correct email address for official communication.

Query: Please note that author's telephone/fax numbers are not published in Journal articles due to the fact that articles are available online and in print for many years, whereas telephone/fax numbers are changeable and therefore not reliable in the long term.

Answer: We thank the editor for this clarification and agree with this point.

Query: Have we correctly interpreted the following funding source(s) you cited in your article: DSM Nutritional Products (Kaiseraugst, Switzerland); Northern Ireland HSC Public Health Agency, Research \& Development Division?

Answer: Yes we confirm that you have correctly interpreted the funding sources cited in our article. 